\title{
OPEN A novel base-metal multifunctional catalyst for the synthesis of 2-amino-3-cyano-4H-chromenes by a multicomponent tandem oxidation process
}

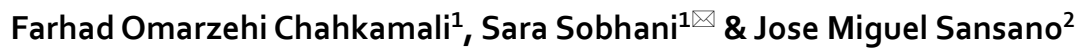

A novel base-metal multifunctional nanomagnetic catalyst is prepared by the immobilization of tungstate anions onto $\gamma-\mathrm{Fe}_{2} \mathrm{O}_{3}$ supported with imidazolium moieties. The $\left(\gamma-\mathrm{Fe}_{2} \mathrm{O}_{3}-\mathrm{Im}-\mathrm{Py}\right)_{2} \mathrm{WO}_{4}$ was fully characterized using FT-IR, XPS, TEM, FESEM, ICP, TGA, VSM and XRD and used as a multifunctional heterogeneous catalyst for the synthesis of 2-amino-3-cyano-4H-chromenes via a multicomponent tandem oxidation process starting from alcohols under solvent-free conditions. During this process, tungstate catalyzes the oxidation of a wide range of alcohols in the presence of TBHP as a clean source. The in-situ formed aldehydes are condensed with malononitrile and $\beta$-dicarbonyl compounds/naphthols/4-hydroxycumarin through promotion by pyridine and imidazolium moieties of the catalyst. By this method, a variety of 2-amino-3-cyano-4H-chromenes are generated in good to high yields from alcohols as inexpensive and easily available starting materials. The catalyst is recovered easily by the aid of an external magnetic field and reused in five successive runs with insignificant decreasing activity.
\end{abstract}

Tandem reactions, which allow multistep reactions in the same vessel, have attracted an enormous attention as they avoid the separation of intermediates and decrease waste production, thus offering many important economic benefits ${ }^{1,2}$. Within tandem reactions, tandem oxidation process (TOP) has arisen as an inventive tool in the synthesis of organic compounds starting from alcohols ${ }^{3}$. Alcohols are the most environmentally benign chemicals in the organic reactions due to the broad accessibility, low expense, opportunity of being generated from renewable biomass materials, low level of poisoning, and simplicity of usage, storage, transport and dissolving ${ }^{4}$. Pioneering works concerning the growth of the TOP has been done by Robert Ireland during his attempts for the synthesis of polyether ionophore antibiotics ${ }^{5}$. A number of volatile aldehydes were produced which made their separation difficult. Ireland solved this problem by Swern oxidation of alcohols and subsequent Wittig reagent addition to in-situ generated aldehydes. Since this discovery, a diversity of worthwhile materials has been synthesized from alcohols by $\mathrm{TOP}^{6-8}$. Recently, TOP has expanded concerning the use of a variety of oxidizing agents and nucleophilic compounds ${ }^{9-13}$. More importantly, expansion of TOP to multicomponent reactions (MCRs) has offered the synthesis of a wide range of novel valuable compounds ${ }^{14-18}$. These processes provide high atom economy, and diminish the number of time-loosing, cost-demanding, waste-generating operations and purification processes in the chemical synthesis ${ }^{19}$. In the past few years many attentions have been paid to the development and application of multifunctional catalysts by placing different types of active sites on one catalyst for using in tandem catalysis process ${ }^{20-22}$. However, the application of multifunctional catalytic systems in the multicomponent TOP starting from alcohols is a new field of studies ${ }^{23-25}$.

Chromene containing compounds are a very important family of heterocycles with wide biological properties and therapeutic applications ${ }^{26-28}$. They exist in the widespread natural compounds and display numerous pharmaceutical properties such as anti-inflammatory, anti-oxidant, anti-bacterial, anti-cancer, anti-coagulant, anti-microbial, anti-Alzheimer and anti-HIV ${ }^{29,30}$. 2-Amino-3-cyano-4H-chromenes are generally prepared by three-component reactions involving the cyclocondensation of various types of aldehydes, malonates and

\footnotetext{
${ }^{1}$ Department of Chemistry, College of Sciences, University of Birjand, Birjand, Iran. ${ }^{2}$ Departamento de Química Orgánica, Facultad de Ciencias, Centro de Innovación en Química Avanzada (ORFEO-CINQA), Universidad de Alicante, Apdo. 99, 03080 Alicante, Spain. ${ }^{\circledR}$ email: ssobhani@birjand.ac.ir
} 


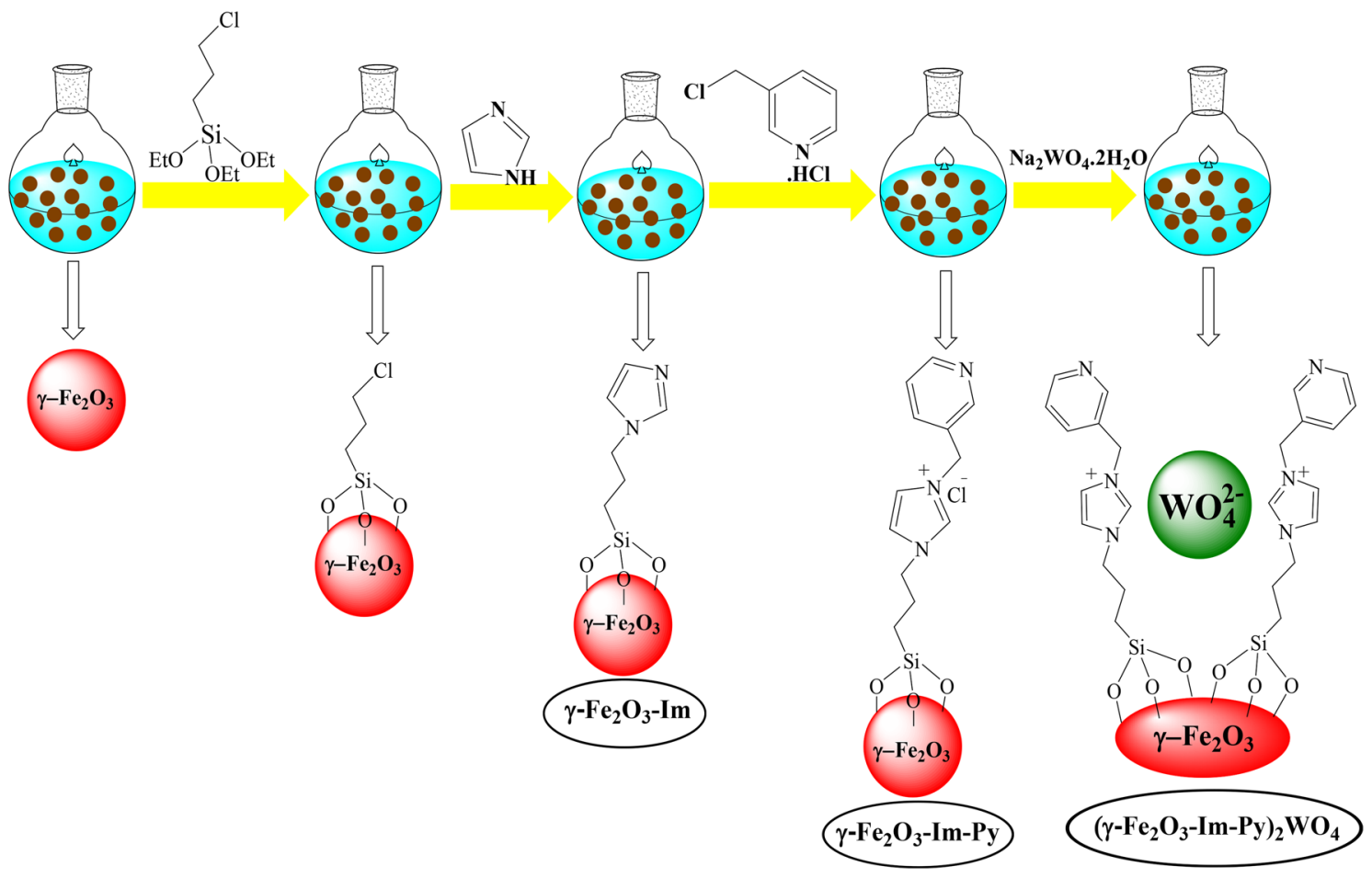

Figure 1. Synthesis of multifunctional $\left(\gamma-\mathrm{Fe}_{2} \mathrm{O}_{3}-\mathrm{Im}-\mathrm{Py}\right)_{2} \mathrm{WO}_{4}$.

$\beta$-dicarbonyl compounds or activated phenols ${ }^{31}$. Numerous modified catalysts have been used for the elaboration of 2-amino-3-cyano- $4 H$-chromenes and their derivatives ${ }^{32-37}$. Most of the reports suffer from drawbacks e.g., long reaction times, difficult workup procedures, use of unrecyclable catalyst and afford only moderate yields of the products. 2-Amino-3-cyano-4H-chromenes can also be prepared from alcohols via multicomponent TOP reactions. This method passes through three sequential steps: (1) oxidation of alcohols to aldehydes which requires an oxidizing catalyst, (2) Knoevenagel condensation of the in-situ formed aldehydes with malononitrile, (3) Michael addition of $\beta$-dicarbonyl compounds followed by cyclization reaction. The last two steps can be promoted by acidic and/or basic catalysts. Based on a literature survey, there is a few reports on the preparation of 2-amino-3-cyano- $4 H$-chromene starting from alcohol ${ }^{38-41}$. Within these reports, there is only one report on using a bifunctional catalyst for the preparation of these targeted scaffolds ${ }^{41}$. These methods suffered from several drawbacks such as using expensive oxidizing agent, requiring $\mathrm{pH}$ adjustment, time-consuming catalyst isolation, limited activated nucleophiles/alcohols and long reaction time.

The high selective and controllable oxidation of alcohols to corresponding aldehydes is one of the predominant and challenging reactions in synthetic chemistry ${ }^{42,43}$. The classical oxidation methods include the use of stoichiometric amounts of strong oxidants such as chromium (VI) or manganese (VII) reagents ${ }^{44,45}$ and concentrated $\mathrm{HNO}_{3}{ }^{46}$ which are environmentally hazardous and produce large amounts of toxic wastes. A green protocol to replace the classical method for oxidation reaction is using oxidation metal catalysts ${ }^{47-49}$. However, while various catalytic systems including molybdenum ${ }^{50}$, manganese ${ }^{51}$, iron $^{52}$, palladium ${ }^{53}$, rhenium ${ }^{54}$, ruthenium ${ }^{55}$, and copper $^{56}$, have been well explored, catalytic systems based on tungsten have been particularly received a great deal of attentions to achieve high efficiency and selectivity in the oxidation of alcohols ${ }^{57,58}$. As there is a difference in solubility of tungstate anion and organic substrates, the use of ionic liquids containing tungstate anions has attracted much attention for the oxidation of alcohols due to the unique property of ionic liquids (ILs) as a phase transfer catalyst under organic-inorganic media ${ }^{59-62}$. On the other hand, immobilization of tungsten species onto solid supports has been evolving to overcome the difficult separation of catalyst and products under similar homogeneous conditions. Along this line, several heterogeneous imidazolium-based ILs containing tungstate anions have been introduced for the selective oxidation of alcohols ${ }^{63-65}$.

Recently, we have prepared two new magnetically separable functionalized $\mathrm{Pd}-\mathrm{N}$-heterocyclic carbene (NHC) starting from supported imidazolium salts on magnetic iron oxide (MNPs) and reported their applications in several organic transformations ${ }^{66,67}$. In our reported catalysts, we have profited from the presence of two nitrogen atoms in imidazole for the immobilization of imidazole onto a MNPs as a solid support on one side and then functionalization of supported imidazolium salts on the other side. Following our attempts for the developing multifunctional heterogeneous catalysts in organic reactions ${ }^{68-70}$, herein, we have tried to design a new base-metal multifunctional catalyst from supported imidazole onto MNPs for the generation of 2-amino3-cyano-4H-chromenes via a three-component TOP starting from alcohols. For this purpose, at first the free nitrogen of supported imidazole was functionalized with pyridine by the reaction with 3-(chloromethyl) pyridine hydrochloride and then the chloride anion in the resulting imidazolium ILs was exchanged with tungstate to produce $\left(\gamma-\mathrm{Fe}_{2} \mathrm{O}_{3}-\mathrm{Im}-\mathrm{Py}\right)_{2} \mathrm{WO}_{4}$ (Fig. 1). In this catalyst, we predicted that tungstate anions will promote 
the selective oxidation of alcohols to aldehydes and pyridine will activate Knoevenagel condensation-Michael addition-cyclization reaction of in-situ formed aldehydes with malononitrile and dimedone.

\section{Experimental}

General information. All Chemicals and solvents were bought from Merck Chemical Company. The product purity and the reaction progress were investigated by TLC using silica gel polygram SILG/UV254 plates. The Fourier transform infrared (FT-IR) spectra were recorded on a Shimadzu Fourier Transform Infrared Spectrophotometer (FT-IR-8300). X-ray photoelectron spectroscopy (XPS) analyses were accomplished using a VGMicrotech Multilab 3000 spectrometer, equipped with an $\mathrm{Al}$ anode. The deconvolution of spectra was performed by using Gaussian Lorentzian curves. The content of W in the catalyst was determined by OPTIMA 5300DV ICP analyzer. The transmission electron microscopy (TEM) analysis was performed using Philips EM208S operating at $100 \mathrm{kV}$. FESEM were achieved using a TESCAN MIRA3. Thermo-gravimetric analysis (TGA) was carried out using TA-Q600. The vibrating sample magnetometer (VSM) analysis was performed using Lake Shore Cryotronics 7407. X-ray diffraction (XRD) analysis was performed using XRD Philips PW1730. Melting points were measured by an electrothermal 9100 apparatus.

Synthesis of chloro-functionalized $\boldsymbol{\gamma}-\mathrm{Fe}_{2} \mathrm{O}_{3}{ }^{71}$. At first, $\gamma-\mathrm{Fe}_{2} \mathrm{O}_{3}(2.0 \mathrm{~g})$ was dispersed in dry toluene $(40 \mathrm{~mL})$ by sonication for $45 \mathrm{~min}$. 3-Chloropropyl triethoxysilane $(3 \mathrm{~mL})$ was slowly added and stirred while it was heated to $105^{\circ} \mathrm{C}$. Then, the stirring was continued for $48 \mathrm{~h}$ at the same temperature. Chloro-functionalized $\gamma-\mathrm{Fe}_{2} \mathrm{O}_{3}$ was obtained after separation of the solid using an external magnetic field, washing with diethyl ether and dichloromethane, and vacuum-dried.

Synthesis of imidazole supported on $\gamma-\mathrm{Fe}_{2} \mathrm{O}_{3}\left(\gamma-\mathrm{Fe}_{2} \mathrm{O}_{3}-\mathrm{Im}\right)^{66}$. Chloro-functionalized $\gamma-\mathrm{Fe}_{2} \mathrm{O}_{3}$ $(1.6 \mathrm{~g})$ was dispersed in toluene $(30 \mathrm{~mL}$, dry) by sonication $(30 \mathrm{~min})$. While the mixture was stirred, imidazole $(0.204 \mathrm{~g}, 3 \mathrm{mmol})$ was added and then refluxed at $110^{\circ} \mathrm{C}$. After $24 \mathrm{~h}, \mathrm{Et}_{3} \mathrm{~N}(0.43 \mathrm{~mL}, 3 \mathrm{mmol})$ was added to the cooled mixture and stirred $(30 \mathrm{~min})$. The solid material was isolated using an external magnet, washed with water $(3 \times 10 \mathrm{~mL})$ and acetone $(3 \times 10 \mathrm{~mL})$ and dried in a vacuum oven $\left(70^{\circ} \mathrm{C}\right)$.

Synthesis of $\boldsymbol{\gamma}-\mathrm{Fe}_{2} \mathrm{O}_{3}-\mathrm{Im}-\mathrm{Py}$. The synthesized $\gamma$ - $\mathrm{Fe}_{2} \mathrm{O}_{3}$ - $\mathrm{Im}(1.5 \mathrm{~g})$ was dispersed in toluene (30 mL, dry) by sonication (30 min). 3-(Chloromethyl) pyridine hydrochloride $(0.492 \mathrm{~g}, 3 \mathrm{mmol})$ and $\mathrm{Et}_{3} \mathrm{~N}(0.43 \mathrm{~mL}, 3 \mathrm{mmol})$ was added and refluxed at $110^{\circ} \mathrm{C}$. After $24 \mathrm{~h}$, the solid was isolated by an external magnet, washed with $\mathrm{H}_{2} \mathrm{O}$ $(3 \times 10 \mathrm{~mL}), \mathrm{EtOH}(2 \times 10 \mathrm{~mL})$ and acetone $(2 \times 10 \mathrm{~mL})$ and dried in a vacuum oven $\left(70^{\circ} \mathrm{C}\right)$.

Synthesis of $\left(\boldsymbol{\gamma}-\mathrm{Fe}_{2} \mathrm{O}_{3}-\mathrm{Im}-\mathrm{Py}\right)_{2} \mathbf{W O}_{4}$. The synthesized $\boldsymbol{\gamma}-\mathrm{Fe}_{2} \mathrm{O}_{3}$-Im-Py $(1 \mathrm{~g})$ was dispersed in $\mathrm{H}_{2} \mathrm{O}(25 \mathrm{~mL}$, deionized) by sonication (30 min). $\mathrm{Na}_{2} \mathrm{WO}_{4} \cdot 2 \mathrm{H}_{2} \mathrm{O}(1.319 \mathrm{~g}, 4 \mathrm{mmol})$ was added and stirred at ambient temperature. After $48 \mathrm{~h}$, the resulting compound was isolated using an external magnet and washed with $\mathrm{H}_{2} \mathrm{O}(3 \times 10 \mathrm{~mL})$ and ethanol $(2 \times 10 \mathrm{~mL})$ to eliminate the unreacted $\mathrm{Na}_{2} \mathrm{WO}_{4} \cdot 2 \mathrm{H}_{2} \mathrm{O}$ and dried in a vacuum oven $\left(70{ }^{\circ} \mathrm{C}\right)$.

Synthesis of $\left(\gamma-\mathrm{Fe}_{2} \mathrm{O}_{3}-\mathrm{Im}-\mathrm{Py}\right)_{2} \mathrm{MoO}_{4}$. The synthesized $\gamma-\mathrm{Fe}_{2} \mathrm{O}_{3}-\mathrm{Im}$-Py $(1 \mathrm{~g})$ was dispersed in $\mathrm{H}_{2} \mathrm{O}$ ( $25 \mathrm{~mL}$, deionized) by sonication $(30 \mathrm{~min})$. $\mathrm{Na}_{2} \mathrm{MoO}_{4} \cdot 2 \mathrm{H}_{2} \mathrm{O}(0.968 \mathrm{~g}, 4 \mathrm{mmol})$ was added and stirred at ambient temperature. After $48 \mathrm{~h}$, the resulting compound was isolated using an external magnet and washed with $\mathrm{H}_{2} \mathrm{O}$ $(3 \times 10 \mathrm{~mL})$ and ethanol $(2 \times 10 \mathrm{~mL})$ to eliminate the unreacted $\mathrm{Na}_{2} \mathrm{MoO}_{4} \cdot 2 \mathrm{H}_{2} \mathrm{O}$ and dried in a vacuum oven $\left(70{ }^{\circ} \mathrm{C}\right)$. ICP analysis of the resulting $\left(\gamma-\mathrm{Fe}_{2} \mathrm{O}_{3}-\mathrm{Im}-\mathrm{Py}\right)_{2} \mathrm{MoO}_{4}$ indicated that $0.31 \mathrm{mmol}(0.0297 \mathrm{mg})$ molybdate was immobilized on $1 \mathrm{gr}$ of this compound.

Synthesis of $\boldsymbol{\gamma}-\mathrm{Fe}_{2} \mathrm{O}_{3}-\mathrm{Im}-\mathrm{Py}-\mathrm{VO}_{3}$. The synthesized $\boldsymbol{\gamma}-\mathrm{Fe}_{2} \mathrm{O}_{3}$-Im-Py $(1 \mathrm{~g})$ was dispersed in $\mathrm{H}_{2} \mathrm{O}(25 \mathrm{~mL}$, deionized) by sonication $(30 \mathrm{~min}) . \mathrm{NaVO}_{3}(0.487 \mathrm{~g}, 4 \mathrm{mmol})$ was added and stirred at ambient temperature. After $48 \mathrm{~h}$, the resulting compound was isolated using an external magnet and washed with $\mathrm{H}_{2} \mathrm{O}(3 \times 10 \mathrm{~mL})$ and ethanol $(2 \times 10 \mathrm{~mL})$ to eliminate the unreacted $\mathrm{NaVO}_{3}$ and dried in a vacuum oven $\left(70{ }^{\circ} \mathrm{C}\right)$. ICP analysis of the resulting $\gamma-\mathrm{Fe}_{2} \mathrm{O}_{3}$ - Im- $\mathrm{Py}-\mathrm{VO}_{3}$ indicated that $0.64 \mathrm{mmol}(0.0326 \mathrm{mg})$ vanadate was immobilized on $1 \mathrm{gr}$ of this compound.

Synthesis of $\boldsymbol{\gamma}-\mathrm{Fe}_{2} \mathrm{O}_{3}-\mathrm{Im}-\mathrm{Me}^{66} . \quad \gamma-\mathrm{Fe}_{2} \mathrm{O}_{3}$-Im $(1 \mathrm{~g})$ was dispersed in toluene $(30 \mathrm{~mL}$, dry) by sonication $(30 \mathrm{~min})$. Methyl iodide $(0.25 \mathrm{~mL}, 4 \mathrm{mmol})$ was added and stirred under reflux conditions at $110^{\circ} \mathrm{C}$. After $24 \mathrm{~h}$, the solid was collected using an external magnet, washed with diethyl ether $(3 \times 10 \mathrm{~mL})$ and acetone $(3 \times 10 \mathrm{~mL})$ and dried in a vacuum oven $\left(70^{\circ} \mathrm{C}\right)$.

Synthesis of $\left(\boldsymbol{\gamma}-\mathrm{Fe}_{2} \mathrm{O}_{3}-\mathrm{Im}-\mathrm{Me}\right)_{2} \mathbf{W O}_{4}$. The synthesized $\gamma$ - $\mathrm{Fe}_{2} \mathrm{O}_{3}$-Im-Me $(1 \mathrm{~g})$ was dispersed in $\mathrm{H}_{2} \mathrm{O}$ $\left(25 \mathrm{~mL}\right.$, deionized) by sonication $(30 \mathrm{~min}) \cdot \mathrm{Na}_{2} \mathrm{WO}_{4} \cdot 2 \mathrm{H}_{2} \mathrm{O}(1.319 \mathrm{~g}, 4 \mathrm{mmol})$ was added and stirred at room temperature. After $48 \mathrm{~h}$, by means of an external magnet, the resulting compound was isolated and washed with $\mathrm{H}_{2} \mathrm{O}(3 \times 10 \mathrm{~mL})$ and ethanol $(2 \times 10 \mathrm{~mL})$ to eliminate the unreacted $\mathrm{Na}_{2} \mathrm{WO}_{4} \cdot 2 \mathrm{H}_{2} \mathrm{O}$ and dried in a vacuum oven $\left(70{ }^{\circ} \mathrm{C}\right)$.

Catalytic performance of $\left(\boldsymbol{\gamma}-\mathrm{Fe}_{2} \mathrm{O}_{3}-\mathrm{Im}-\mathrm{Py}\right)_{2} \mathbf{W O}_{4}$. General procedure for the oxidation of alcohols. A mixture of alcohol (1 mmol), tert-butyl hydroperoxide (TBHP) $(6 \mathrm{mmol})$ and $\left(\gamma-\mathrm{Fe}_{2} \mathrm{O}_{3}-\mathrm{Im}-\mathrm{Py}\right)_{2} \mathrm{WO}_{4}(2 \mathrm{~mol} \%$, $57 \mathrm{mg}$ ) was stirred under solvent-free conditions at $90{ }^{\circ} \mathrm{C}$. The progress of the reaction was monitored by TLC. After requisite time (Table 2), the reaction mixture was cooled to ambient temperature. EtOAc (5 mL) 


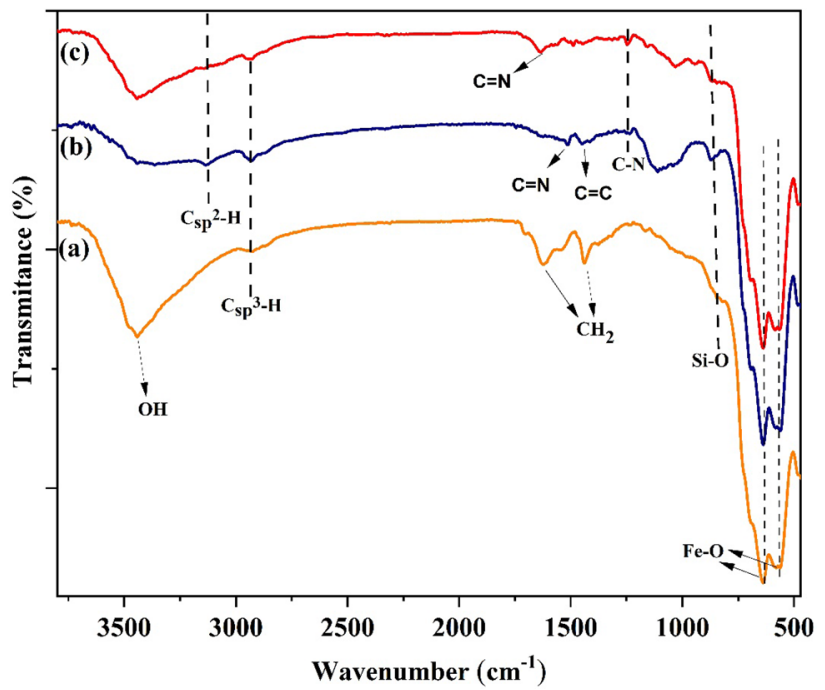

Figure 2. FT-IR spectra of (a) chloro-functionalized- $\gamma$ - $\mathrm{Fe}_{2} \mathrm{O}_{3},(\mathbf{b}) \gamma-\mathrm{Fe}_{2} \mathrm{O}_{3}-\mathrm{Im}$ and $(\mathbf{c})\left(\gamma-\mathrm{Fe}_{2} \mathrm{O}_{3}-\mathrm{Im}-\mathrm{Py}\right)_{2} \mathrm{WO}_{4}$.
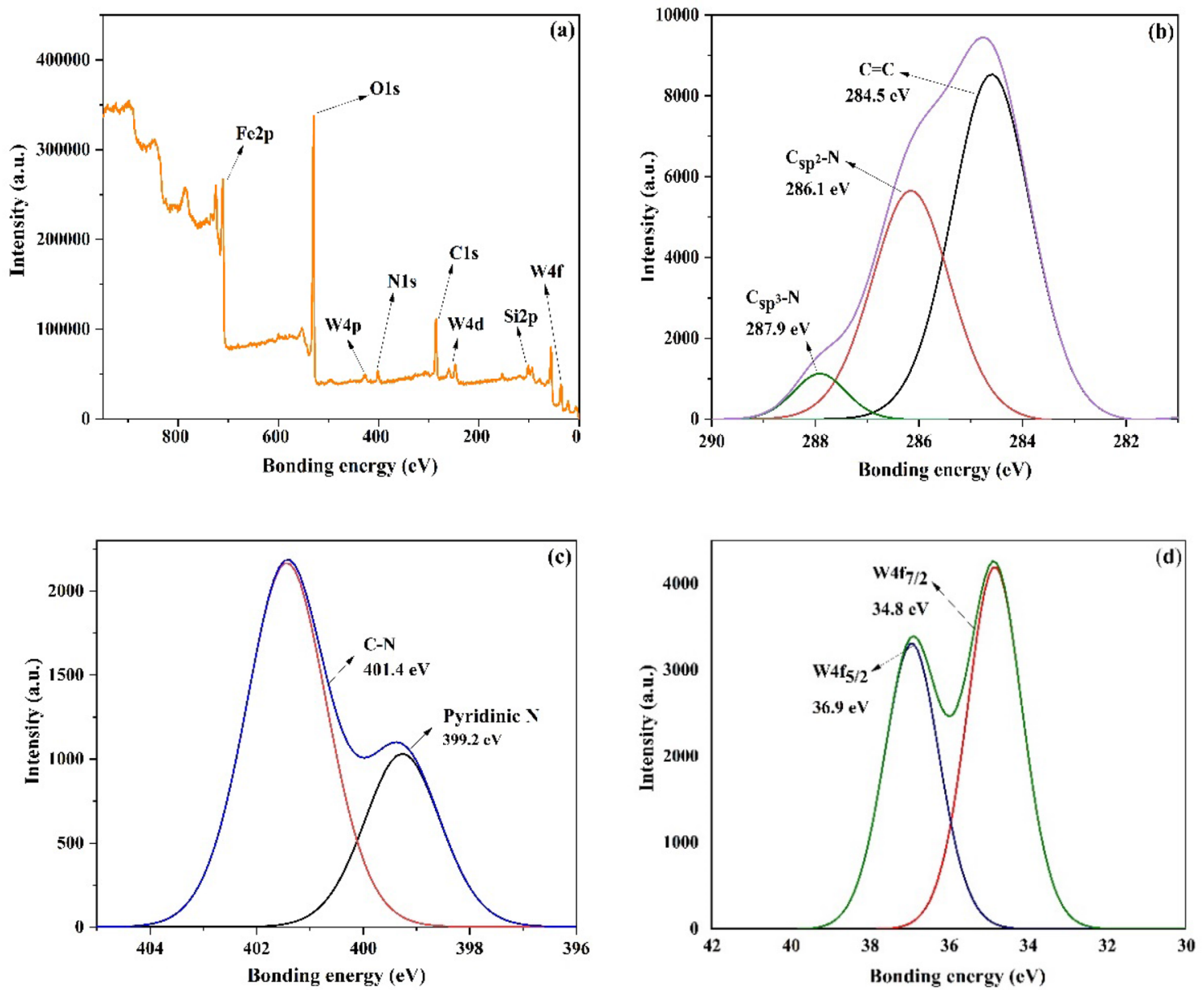

Figure 3. XPS spectra of (a) $\left(\gamma-\mathrm{Fe}_{2} \mathrm{O}_{3}-\mathrm{Im}-\mathrm{Py}\right)_{2} \mathrm{WO}_{4}$, (b) $\mathrm{C} 1 \mathrm{~s}$, (c) N1s and (d) W4f.

was added to the reaction mixture. $\left(\gamma-\mathrm{Fe}_{2} \mathrm{O}_{3}-\mathrm{Im}-\mathrm{Py}\right)_{2} \mathrm{WO}_{4}$ was isolated using an external magnet, washed with EtOAc $(2 \times 5 \mathrm{~mL})$ and $\mathrm{EtOH}(2 \times 5 \mathrm{~mL})$, vacuum dried, and recycled for the next run. The combined organic layer was then dried using $\mathrm{Na}_{2} \mathrm{SO}_{4}$. After solvent evaporation, a crude product was obtained. The pure product was achieved by column chromatography on silica gel eluting $n$-hexane/EtOAc (10:2). 

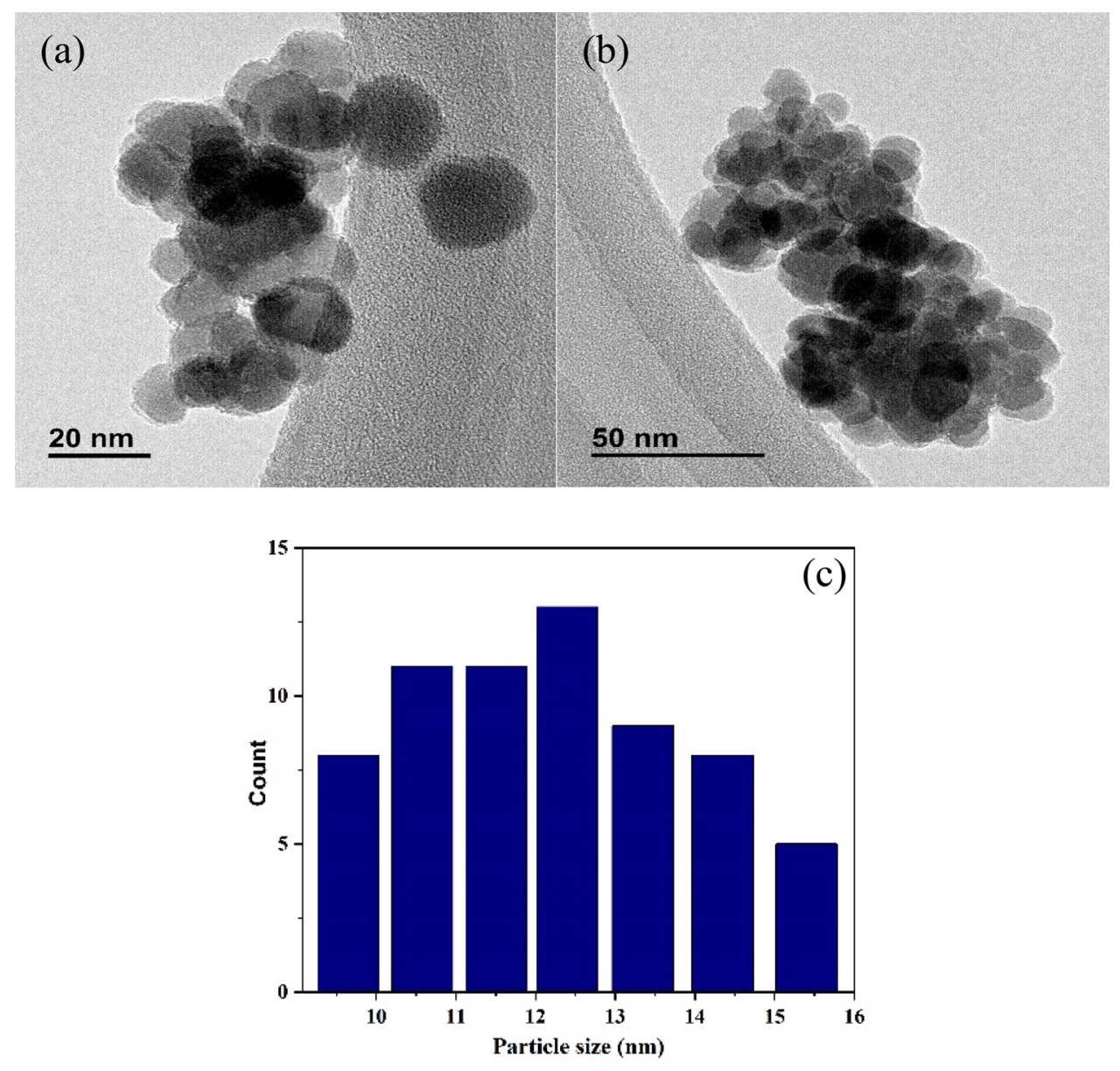

Figure 4. (a,b) TEM images and (c) particle size distribution histogram of $\left(\gamma-\mathrm{Fe}_{2} \mathrm{O}_{3}-\mathrm{Im}-\mathrm{Py}\right)_{2} \mathrm{WO}_{4}$.

General procedure for the three-component TOP synthesis of 2-amino-3-cyano-4H-chromene catalyzed by $\left(\gamma-\mathrm{Fe}_{2} \mathrm{O}_{3}-\mathrm{Im}-\mathrm{Py}\right)_{2} \mathrm{WO}_{4}$. In a round-bottomed flask, alcohol $(1 \mathrm{mmol})$, tert-butyl hydroperoxide (TBHP) $(6 \mathrm{mmol})$ and $\left(\gamma-\mathrm{Fe}_{2} \mathrm{O}_{3}-\mathrm{Im}-\mathrm{Py}\right)_{2} \mathrm{WO}_{4}(5 \mathrm{~mol} \%, 142 \mathrm{mg})$ were mixed and stirred at $90{ }^{\circ} \mathrm{C}$ for a defined time (Table 4, Figs. 10 and 11). Then, malononitrile $(1.2 \mathrm{mmol})$ and $\beta$-dicarbonyl compounds/naphthols/4-hydroxycumarin $(1.2 \mathrm{mmol})$ was added and stirred at $90{ }^{\circ} \mathrm{C}$ for an appropriate time (Table 4, Figs. 10 and 11). After cooling the reaction mixture to ambient temperature, EtOAc $(10 \mathrm{~mL})$ was added and the catalyst was collected by an external magnet. It was washed with EtOAc $(2 \times 5 \mathrm{~mL})$, EtOH $(2 \times 5 \mathrm{~mL})$, dried and reused for the next run under the same reaction conditions. The combined organic solvents were vacuum evaporated to produce a crude product. Column chromatography on $\mathrm{SiO}_{2}$ eluting with $n$-hexane/EtOAc (7:3) produces the pure product. The products were characterized by ${ }^{1} \mathrm{H}$ NMR spectra (Supplementary Figs. S1-S14).

\section{Results and discussion}

Synthesis and characterization of the multifunctional $\left(\gamma-\mathrm{Fe}_{2} \mathrm{O}_{3}-\mathrm{Im}-\mathrm{Py}\right)_{2} \mathbf{W O}_{4}$. We have prepared $\left(\gamma-\mathrm{Fe}_{2} \mathrm{O}_{3}-\mathrm{Im}-\mathrm{Py}\right)_{2} \mathrm{WO}_{4}$ following the steps designated in Fig. 1. In the first step, $\gamma-\mathrm{Fe}_{2} \mathrm{O}_{3}$ was functionalized by the reaction with 3-chloropropyltriethoxysilane. Then, the reaction of chloro-functionalized- $\gamma-\mathrm{Fe}_{2} \mathrm{O}_{3}$ with imidazole led to the formation of $\gamma-\mathrm{Fe}_{2} \mathrm{O}_{3}$-Im. Imidazole moiety in the $\gamma-\mathrm{Fe}_{2} \mathrm{O}_{3}$-Im was functionalized by the reaction with 3-(chloromethyl) pyridine hydrochloride to give $\gamma-\mathrm{Fe}_{2} \mathrm{O}_{3}$-Im-Py. Finally, $\left(\gamma-\mathrm{Fe}_{2} \mathrm{O}_{3}-\mathrm{Im}-\mathrm{Py}\right)_{2} \mathrm{WO}_{4}$ was prepared by mixing $\gamma-\mathrm{Fe}_{2} \mathrm{O}_{3}$-Im-Py with $\mathrm{Na}_{2} \mathrm{WO}_{4} \cdot 2 \mathrm{H}_{2} \mathrm{O}$. The synthesized $\left(\gamma-\mathrm{Fe}_{2} \mathrm{O}_{3}-\mathrm{Im}-\mathrm{Py}\right)_{2} \mathrm{WO}_{4}$ was characterized by a variety of techniques such as FT-IR, XPS, TEM, FESEM, ICP, VSM, TGA and XRD. The FT-IR spectra of chloro-functionalized $-\gamma-\mathrm{Fe}_{2} \mathrm{O}_{3}, \gamma-\mathrm{Fe}_{2} \mathrm{O}_{3}$ - Im and $\left(\gamma-\mathrm{Fe}_{2} \mathrm{O}_{3}-\mathrm{Im}-\mathrm{Py}\right)_{2} \mathrm{WO}_{4}$ are presented in Fig. 2 . The absorption bands at about 560-640, 875 and $2935 \mathrm{~cm}^{-1}$ were related to the stretching vibrations of the $\mathrm{Fe}-\mathrm{O}$, $\mathrm{Si}-\mathrm{O}$ and $\mathrm{Csp}^{3}-\mathrm{H}$ bonds, respectively. In the spectrum of $\gamma-\mathrm{Fe}_{2} \mathrm{O}_{3}$-Im and $\left(\gamma-\mathrm{Fe}_{2} \mathrm{O}_{3}-\mathrm{Im}-\mathrm{Py}\right)_{2} \mathrm{WO}_{4}$, the absorption bands at around 1250 and $3135 \mathrm{~cm}^{-1}$ were allocated to the stretching vibration of $\mathrm{C}-\mathrm{N}$ and $\mathrm{Csp}^{2}-\mathrm{H}$ bonds. Peaks appeared at 1530 and $1430 \mathrm{~cm}^{-1}$ in the FT-IR of $\gamma-\mathrm{Fe}_{2} \mathrm{O}_{3}$-Im were assigned to the stretching vibration of $\mathrm{C}=\mathrm{N}$ and $\mathrm{C}=\mathrm{C}$ bonds in the imidazole. These absorption bands occurred at around 1630 and $1440-1490 \mathrm{~cm}^{-1}$ in the FT-IR spectrum of $\left(\gamma-\mathrm{Fe}_{2} \mathrm{O}_{3}-\mathrm{Im}-\mathrm{Py}\right)_{2} \mathrm{WO}_{4}$, and confirmed the presence of both imidazole and pyridine anchored on the surface. 

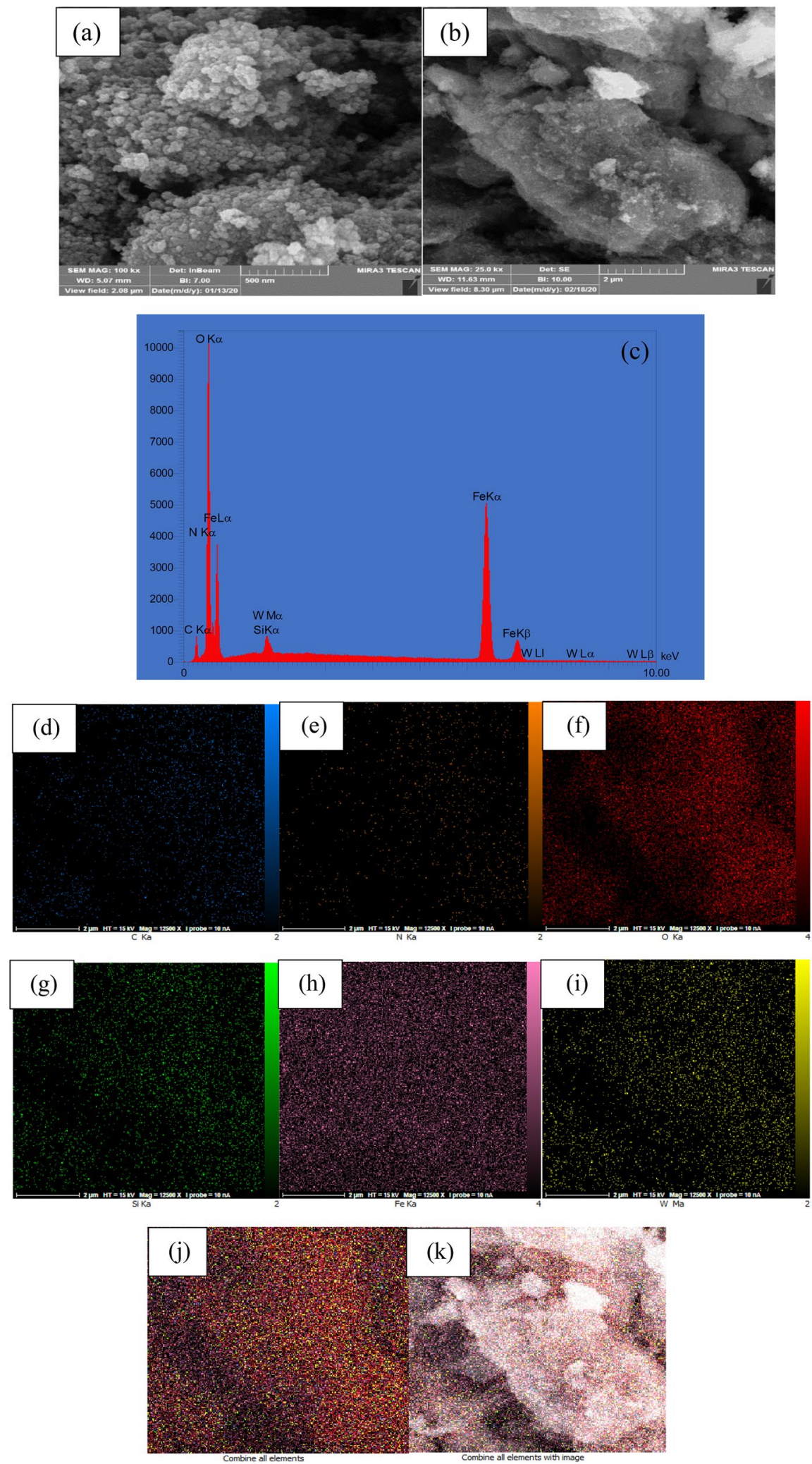

Figure 5. (a,b) FESEM images of $\left(\gamma-\mathrm{Fe}_{2} \mathrm{O}_{3}-\mathrm{Im}-\mathrm{Py}\right)_{2} \mathrm{WO}_{4}$, (c) EDX spectrum and the corresponding quantitative EDS element mapping of (d) C, (e) N, (f) $\mathrm{O},(\mathbf{g}) \mathrm{Si},(\mathbf{h}) \mathrm{Fe}$, (i) W and (j,k) all elements. 


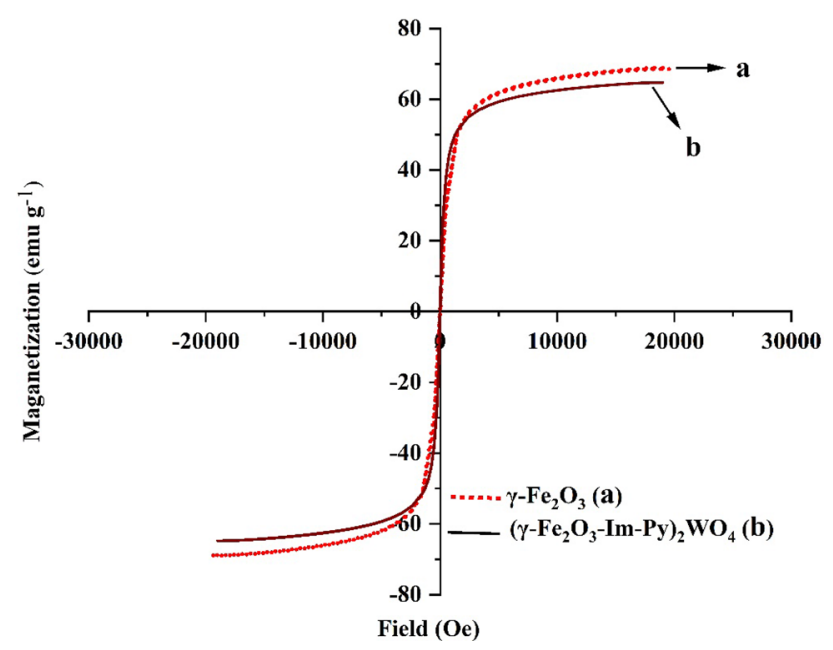

Figure 6. Magnetization curves of (a) $\gamma-\mathrm{Fe}_{2} \mathrm{O}_{3}$ and $(\mathbf{b})\left(\gamma-\mathrm{Fe}_{2} \mathrm{O}_{3}-\mathrm{Im}-\mathrm{Py}\right)_{2} \mathrm{WO}_{4}$.

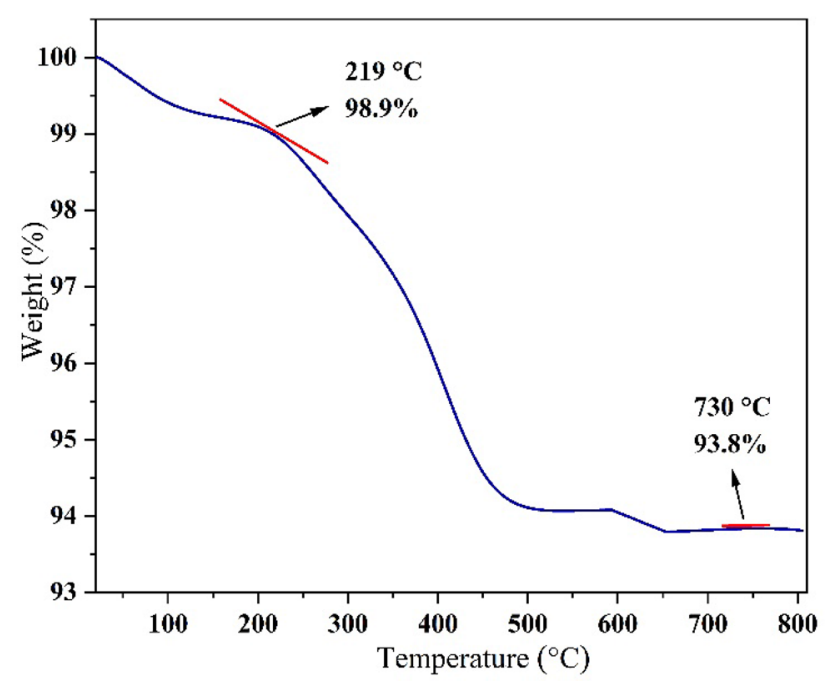

Figure 7. TGA of $\left(\gamma-\mathrm{Fe}_{2} \mathrm{O}_{3}-\mathrm{Im}-\mathrm{Py}\right)_{2} \mathrm{WO}_{4}$.

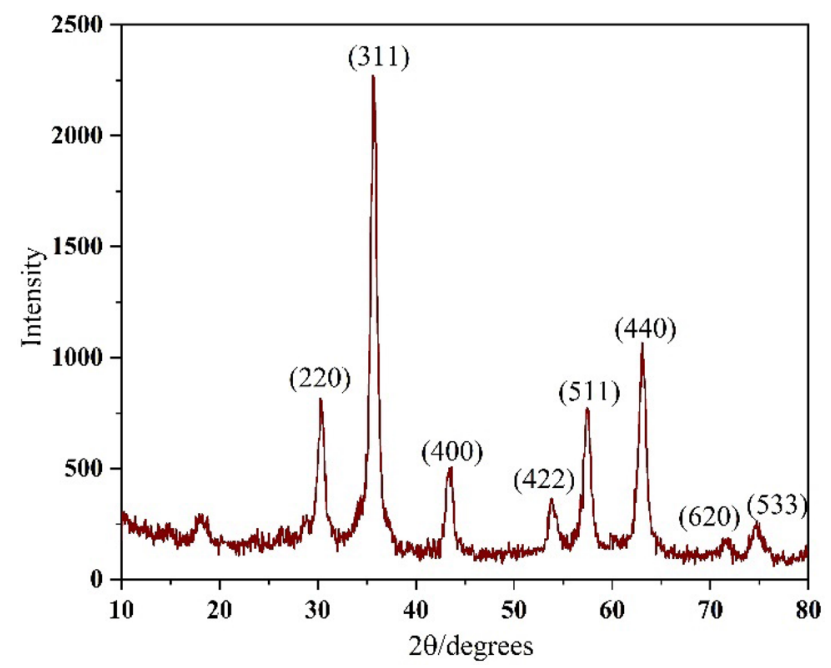

Figure 8. XRD pattern of $\left(\gamma-\mathrm{Fe}_{2} \mathrm{O}_{3}-\mathrm{Im}-\mathrm{Py}\right)_{2} \mathrm{WO}_{4}$. 


\begin{tabular}{|l|l|l|l|l|l|l|}
\hline Entry & Catalyst $^{\mathbf{a}}(\mathbf{m o l}$ ) & Oxidant (equiv.) & Solvent & Temperature $\left({ }^{\circ} \mathbf{C}\right)$ & Time (h) & Yield $\mathbf{~}^{\mathbf{6})}$ \\
\hline 1 & 1.5 & $\mathrm{H}_{2} \mathrm{O}_{2}(6)$ & $\mathrm{H}_{2} \mathrm{O}$ & 90 & 5 & 65 \\
\hline 2 & 1.5 & TBHP (6) & $\mathrm{H}_{2} \mathrm{O}$ & 90 & 6 & 79 \\
\hline 3 & 1.5 & Oxane (6) & $\mathrm{H}_{2} \mathrm{O}$ & 90 & 8 & 50 \\
\hline 4 & 1.5 & Air & $\mathrm{H}_{2} \mathrm{O}$ & 90 & 24 & 55 \\
\hline 5 & 1.5 & $\mathrm{O}_{2}$ (balloon) & $\mathrm{H}_{2} \mathrm{O}$ & 90 & 10 & 68 \\
\hline 6 & 1.5 & TBHP (6) & - & 90 & 4 & 87 \\
\hline 7 & 1.5 & TBHP (6) & $\mathrm{CH}_{3} \mathrm{CN}$ & $-{ }^{c}$ & 5 & 80 \\
\hline 8 & 1.5 & TBHP (6) & $\mathrm{EtOH}^{\mathrm{c}}$ & $-{ }^{\mathrm{c}}$ & 7 & 62 \\
\hline 9 & 2 & TBHP (6) & - & 90 & 3 & 98 \\
\hline 10 & 1 & TBHP (6) & - & 90 & 10 & 75 \\
\hline 11 & 2 & TBHP (6) & - & 70 & 5 & 83 \\
\hline 12 & 2 & TBHP (6) & - & 50 & 8 & 55 \\
\hline 13 & 2 & TBHP (6) & - & r.t & 24 & 40 \\
\hline 14 & 2 & TBHP (4) & - & 90 & 5 & 80 \\
\hline 15 & 2 & TBHP (2) & - & 90 & 10 & 45 \\
\hline 16 & 2 & - & - & 90 & 24 & 15 \\
\hline
\end{tabular}

Table 1. Optimization of reaction conditions in the oxidation of benzyl alcohol catalyzed by $\left(\gamma-\mathrm{Fe}_{2} \mathrm{O}_{3}\right.$-Im$\mathrm{Py}_{2} \mathrm{WO}_{4} \cdot{ }^{\mathrm{a}}$ Based on $\mathrm{W}$ content. ${ }^{\mathrm{b}}$ Isolated yield. Reaction conditions: benzyl alcohol $(1 \mathrm{mmol})$, solvent $(3 \mathrm{~mL})$. 'Reflux.

XPS spectrum of $\left(\gamma-\mathrm{Fe}_{2} \mathrm{O}_{3} \text {-Im-Py }\right)_{2} \mathrm{WO}_{4}$ and the detailed XPS spectra for each element are presented in Fig. 3. XPS discovered C1s, O1s, N1s, Fe2p, Si2p, W4p, W4d and W4f states in $\left(\gamma-\mathrm{Fe}_{2} \mathrm{O}_{3}-\mathrm{Im}-\mathrm{Py}\right)_{2} \mathrm{WO}_{4}$ (Fig. 3a). In Fig. 3b, high-resolution $\mathrm{C} 1 \mathrm{~s}$ spectra of the catalyst has three main peaks at $284.5(\mathrm{C}-\mathrm{C}$ and $\mathrm{C}=\mathrm{C}), 286.1\left(\mathrm{Csp}{ }^{2}-\mathrm{N}\right)$ and $287.9 \mathrm{eV}\left(\mathrm{Csp}^{3}-\mathrm{N}\right)^{72}$. The N1s spectrum exhibited two main peaks, revealing the presence of the pyridinic nitrogen $(399.2 \mathrm{eV})$ and $\mathrm{C}-\mathrm{N}(401.4 \mathrm{eV})(\text { Fig. 3c })^{73}$. The XPS spectra of W4f (Fig. 3d) showed two peaks centered at 34.8 and $36.9 \mathrm{eV}$, related to $\mathrm{W}^{6+}\left(\mathrm{W}_{4} \mathrm{f}_{7 / 2}, \mathrm{~W}_{4} \mathrm{f}_{5 / 2}\right)^{74}$.

ICP analysis of $\left(\gamma-\mathrm{Fe}_{2} \mathrm{O}_{3} \text {-Im-Py }\right)_{2} \mathrm{WO}_{4}$ indicated that $0.35 \mathrm{mmol}(0.064 \mathrm{mg})$ tungstate was immobilized on 1 gr of this compound. The size and morphology of $\left(\gamma-\mathrm{Fe}_{2} \mathrm{O}_{3}\right.$-Im-Py) ${ }_{2} \mathrm{WO}_{4}$ were studied using TEM (Fig. 4) and FESEM (Fig. 5). The TEM and FESEM images of $\left(\gamma-\mathrm{Fe}_{2} \mathrm{O}_{3}\right.$-Im-Py) ${ }_{2} \mathrm{WO}_{4}$ exhibit the development of uniform sphere-shaped nanoparticles. The average particle size of $\left(\gamma-\mathrm{Fe}_{2} \mathrm{O}_{3}-\mathrm{Im}-\mathrm{Py}\right)_{2} \mathrm{WO}_{4}$ was assessed as $12.4 \mathrm{~nm}$ using a size distribution histogram (Fig. 4c). Energy-dispersive X-ray spectroscopy (EDS) was done to approve the presence of each element in this compound. The EDS spectrum (Fig. 5c) displays characteristic signals referring to carbon, nitrogen, oxygen, silicon, iron and tungsten, which shows the immobilizing of $\mathrm{WO}_{4}$-Im-Py on the surface of the MNPs. Moreover, elemental mapping was performed to realize the spreading of the elements present in the $\left(\gamma-\mathrm{Fe}_{2} \mathrm{O}_{3}\right.$-Im-Py) ${ }_{2} \mathrm{WO}_{4}$. The elemental mapping images (Fig. 5d-k) reveal uniform distribution of all the elements.

The magnetization curves of $\gamma-\mathrm{Fe}_{2} \mathrm{O}_{3}$ and $\left(\gamma-\mathrm{Fe}_{2} \mathrm{O}_{3}-\mathrm{Im}-\mathrm{Py}\right)_{2} \mathrm{WO}_{4}$ were shown in Fig. 6 . The magnetizations of $\gamma-\mathrm{Fe}_{2} \mathrm{O}_{3}$ and $\left(\gamma-\mathrm{Fe}_{2} \mathrm{O}_{3}-\mathrm{Im}-\mathrm{Py}\right)_{2} \mathrm{WO}_{4}$ are 68.5 and $64.8 \mathrm{emu} / \mathrm{g}$, respectively. These results indicate the paramagnetic nature of the catalyst. Because of the coating of MNPs, the magnetization value of the catalyst is faintly lesser than that of $\gamma-\mathrm{Fe}_{2} \mathrm{O}_{3}$. This low decrease in the magnetization does not affect the catalyst isolation from the reaction.

Thermal stability of $\left(\gamma-\mathrm{Fe}_{2} \mathrm{O}_{3}\right.$-Im-Py) ${ }_{2} \mathrm{WO}_{4}$ was analyzed by thermogravimetry (TGA) under inert atmosphere (nitrogen) using $10{ }^{\circ} \mathrm{C} / \mathrm{min}$ heating slope in the range of 20 to $810^{\circ} \mathrm{C}$. TGA curve of $\left(\gamma-\mathrm{Fe}_{2} \mathrm{O}_{3}-\mathrm{Im}-\mathrm{Py}\right)_{2} \mathrm{WO}_{4}$ (Fig. 7) demonstrates the two-step compound decomposition. A $1.1 \%$ weight loss can be observed below $219^{\circ} \mathrm{C}$, which is due to removal of physically adsorbed water molecules. In the second stage, $5.1 \%$ mass loss can be observed at $219-730^{\circ} \mathrm{C}$ due to the decomposition of organic species supported on the MNPs surface. TGA curve also approves the fruitful loading of organic moiety on the surface of MNPs.

Figure 8 displays the XRD patterns of the $\left(\gamma-\mathrm{Fe}_{2} \mathrm{O}_{3}-\mathrm{Im}-\mathrm{Py}\right)_{2} \mathrm{WO}_{4}$. The diffraction peaks positioned at $30.44^{\circ}$, $35.75^{\circ}, 43.5^{\circ}, 53.9^{\circ}, 57.4^{\circ}, 62.85^{\circ}, 71.75^{\circ}$ and $74.6^{\circ}$, which are indexed to (220), (311), (400), (422), (511), (440), (620) and (533), respectively. Their relative intensities match pretty well with the inverse spinal structure of maghemite according to JCPDS card No. 39-1346 ${ }^{75}$. These observations confirmed the existence of $\gamma-\mathrm{Fe}_{2} \mathrm{O}_{3}$ nanocrystals and indicates that the crystalline phase of $\gamma-\mathrm{Fe}_{2} \mathrm{O}_{3}$ did not alter in the stages of the catalyst synthesis.

Investigation of catalytic activity of the $\left(\mathrm{\gamma}-\mathrm{Fe}_{2} \mathrm{O}_{3}-\mathrm{Im}-\mathrm{Py}\right)_{2} \mathrm{WO}_{4}$ in the synthesis of 2-amino-3-cyano-4H-chromenes via multicomponent TOP. We have firstly investigated the activity of the catalyst for the oxidation of alcohols by choosing benzyl alcohol as a model compound. The influence of diverse oxidants, solvents, temperatures and amounts of the catalyst and the oxidant was examined in the oxidation reaction of benzyl alcohol to benzaldehyde (Table 1). The best result was accomplished using $2 \mathrm{~mol} \%$ of the catalyst and 6 equivalents of TBHP under solvent-free conditions at $90{ }^{\circ} \mathrm{C}$.

To test the generality of this protocol, a diversity of primary and secondary alcohols was allowed to be oxidized under obtained optimum reaction conditions. As shown in Table 2, benzyl alcohols (primary and secondary) were selectively oxidized to aldehydes or ketones in good to high yields (entries 1-18) without any overoxidation 
www.nature.com/scientificreports/

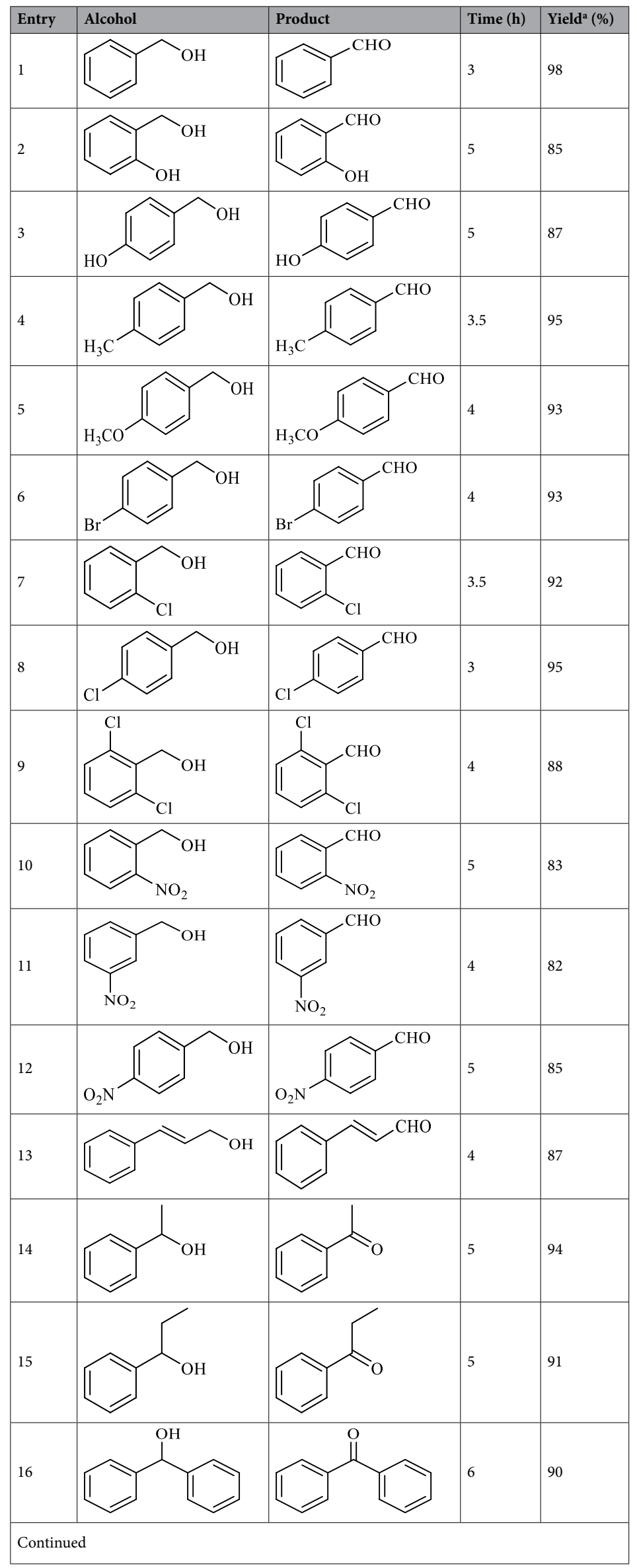

Scientific Reports |

(2022) 12:2867 |

https://doi.org/10.1038/s41598-022-06759-7

natureportfolio

9 


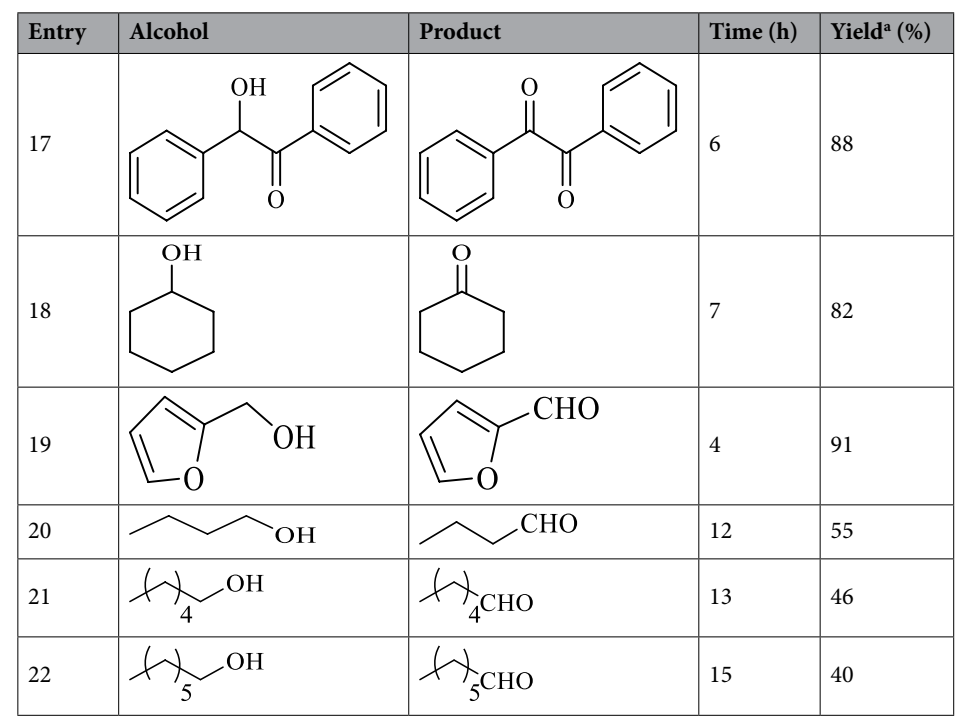

Table 2. Oxidation of alcohols to carbonyl compounds with TBHP catalyzed by $\left(\gamma-\mathrm{Fe}_{2} \mathrm{O}_{3}-\mathrm{Im}-\mathrm{Py}\right)_{2} \mathrm{WO}_{4}$. ${ }^{a}$ Isolated yield. Reaction conditions: benzyl alcohol (1 mmol), TBHP $(6 \mathrm{mmol})$ and $\left(\gamma-\mathrm{Fe}_{2} \mathrm{O}_{3}-\mathrm{Im}-\mathrm{Py}\right)_{2} \mathrm{WO}_{4}(57$ $\mathrm{mg}, 2 \mathrm{~mol} \%$ : based on $\mathrm{W}$ content and relative to alcohol) at $90^{\circ} \mathrm{C}$.<smiles>CC1(C)CC(=O)C2=C(C1)OC(N)=C(C#N)C2c1ccccc1</smiles>

Figure 9. Synthesis of 2-amino-3-cyano-4H-chromenes via multicomponent TOP from benzyl alcohol using different amounts of the catalyst.

\begin{tabular}{|l|l|l|l|}
\hline Entry & Catalyst $^{\mathbf{a}}(\mathbf{m o l} \%)$ & $\operatorname{Time}^{\mathbf{b}}(\mathbf{I}+\mathbf{I I}, \mathbf{h})$ & Isolated yields (\%) \\
\hline 1 & 2 & $3+7$ & 54 \\
\hline 2 & 3 & $2+7$ & 68 \\
\hline 3 & 4 & $2+5$ & 80 \\
\hline 4 & 5 & $1.5+4$ & 91 \\
\hline
\end{tabular}

Table 3. Synthesis of 2-amino-3-cyano- $4 H$-chromenes via multicomponent TOP using different amounts of the catalyst. ${ }^{\mathrm{a}}$ Amount of the catalyst is based on $\mathrm{W}$ content and relative to alcohol. ${ }^{\mathrm{b}}$ Reaction conditions: (I) benzyl alcohol $(1 \mathrm{mmol})$, TBHP $(6 \mathrm{mmol}),\left(\gamma-\mathrm{Fe}_{2} \mathrm{O}_{3}-\mathrm{Im}-\mathrm{Py}\right)_{2} \mathrm{WO}_{4}$, neat, $90^{\circ} \mathrm{C}$; and (II) malononitrile $(1.2$ $\mathrm{mmol})$, dimedone $(1.2 \mathrm{mmol})$, neat, $90^{\circ} \mathrm{C}$.<smiles>[R]COC(=O)C1=C(C)OC(N)=C(C#N)C1[R]</smiles>

Figure 10. Reactions of a variety of aromatic/aliphatic alcohol, malononitrile and $\beta$-dicarbonyl compounds. 


\begin{tabular}{|c|c|c|c|c|c|c|}
\hline \multirow[b]{2}{*}{ Entry } & \multirow[b]{2}{*}{$\mathbf{R}$} & \multirow[b]{2}{*}{$\beta$-dicarbonyl compound } & \multirow[b]{2}{*}{$\operatorname{Time}^{\mathrm{a}}(\mathrm{I}+\mathrm{II}, \mathbf{h})$} & \multirow[b]{2}{*}{ Isolated yields (\%) } & \multicolumn{2}{|l|}{ M.P. $\left({ }^{\circ} \mathrm{C}\right)$} \\
\hline & & & & & Obtained & Reported $^{\text {ref }}$ \\
\hline 1 & $\mathrm{C}_{6} \mathrm{H}_{5}$ & Dimedone & $1.5+4$ & 91 & $224-226$ & $226-227^{76}$ \\
\hline 2 & $4-\mathrm{CH}_{3}-\mathrm{C}_{6} \mathrm{H}_{4}$ & Dimedone & $2+7$ & 84 & $225-227$ & $223-225^{77}$ \\
\hline 3 & $4-\mathrm{OCH}_{3}-\mathrm{C}_{6} \mathrm{H}_{4}$ & Dimedone & $2+7$ & 85 & $191-193$ & $190-192^{76}$ \\
\hline 4 & 2-Cl- $\mathrm{C}_{6} \mathrm{H}_{4}$ & Dimedone & $1.5+6$ & 89 & $214-216$ & $214-215^{78}$ \\
\hline 5 & 4-Cl- $\mathrm{C}_{6} \mathrm{H}_{4}$ & Dimedone & $1.5+5$ & 90 & $238-240$ & $237-239^{78}$ \\
\hline 6 & $2,6-\mathrm{Cl}_{2}-\mathrm{C}_{6} \mathrm{H}_{4}$ & Dimedone & $2.5+6$ & 86 & $235-238$ & $236-238^{79}$ \\
\hline 7 & $4-\mathrm{Br}-\mathrm{C}_{6} \mathrm{H}_{4}$ & Dimedone & $2+7$ & 83 & 202-204 & $203-205^{77}$ \\
\hline 8 & $2-\mathrm{NO}_{2}-\mathrm{C}_{6} \mathrm{H}_{4}$ & Dimedone & $3+6$ & 84 & $227-229$ & $228-229^{78}$ \\
\hline 9 & $3-\mathrm{NO}_{2}-\mathrm{C}_{6} \mathrm{H}_{4}$ & Dimedone & $3+7$ & 83 & $210-211$ & $212-214^{76}$ \\
\hline 10 & $4-\mathrm{NO}_{2}-\mathrm{C}_{6} \mathrm{H}_{4}$ & Dimedone & $3+6$ & 86 & $178-179$ & $179-180^{77}$ \\
\hline 11 & 2 -furyl & Dimedone & $2.5+5.5$ & 88 & $227-229$ & $226-228^{77}$ \\
\hline 12 & $\mathrm{C}_{6} \mathrm{H}_{5} \mathrm{CH}=\mathrm{CH}$ & Dimedone & $3+5$ & 82 & $183-186$ & $182-184^{78}$ \\
\hline $13^{\mathrm{b}}$ & $\mathrm{CH}_{3}\left(\mathrm{CH}_{2}\right)_{6}$ & Dimedone & $10+9$ & 45 & $185-186$ & $187-189^{70}$ \\
\hline 14 & $\mathrm{C}_{6} \mathrm{H}_{5}$ & Cyclohexane-1,3-dione & $1.5+5$ & 89 & $238-240$ & $239-241^{77}$ \\
\hline 15 & $\mathrm{C}_{6} \mathrm{H}_{5}$ & Pentane-2,4-dione & $1.5+5$ & 85 & $161-163$ & $162-163^{70}$ \\
\hline 16 & $\mathrm{C}_{6} \mathrm{H}_{5}$ & Methyl acetoacetate & $1.5+7$ & 84 & $194-196$ & $192-194^{70}$ \\
\hline 17 & $\mathrm{C}_{6} \mathrm{H}_{5}$ & Ethyl acetoacetate & $1.5+6$ & 87 & $190-191$ & $192-194^{78}$ \\
\hline
\end{tabular}

Table 4. Synthesis of chrome-derivatives via multicomponent TOP catalyzed by $\left(\gamma-\mathrm{Fe}_{2} \mathrm{O}_{3}-\mathrm{Im}-\mathrm{Py}\right)_{2} \mathrm{WO}_{4}$. ${ }^{a}$ Reaction conditions: (I) benzyl alcohol $(1 \mathrm{mmol})$, TBHP $(6 \mathrm{mmol}),\left(\gamma-\mathrm{Fe}_{2} \mathrm{O}_{3}-\mathrm{Im}-\mathrm{Py}\right)_{2} \mathrm{WO}_{4}(142 \mathrm{mg}, 5 \mathrm{~mol} \%$; based on $\mathrm{W}$ content and relative to alcohol), and (II) malononitrile (1.2 $\mathrm{mmol})$ and $\beta$-dicarbonyl compounds $(1.2 \mathrm{mmol}) .{ }^{\mathrm{b}}\left(\gamma-\mathrm{Fe}_{2} \mathrm{O}_{3}-\mathrm{Im}-\mathrm{Py}\right)_{2} \mathrm{WO}_{4}(171 \mathrm{mg}, 6 \mathrm{~mol} \%$; based on $\mathrm{W}$ content and relative to alcohol).

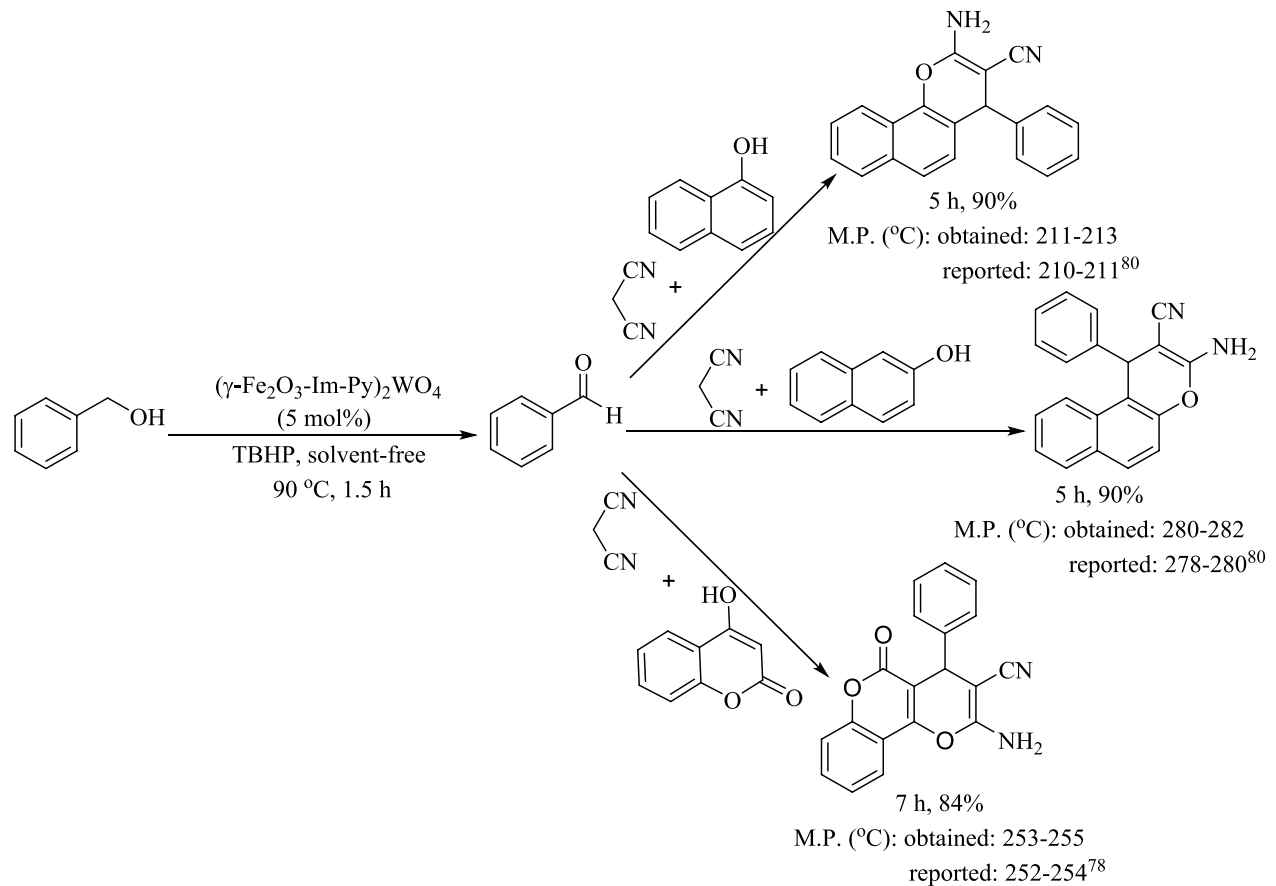

Figure 11. Multicomponent TOP of benzyl alcohol, malononitrile and $\alpha$-naphthol/ $\beta$-naphthol/4hydrxycoumarin catalyzed by $\left(\gamma-\mathrm{Fe}_{2} \mathrm{O}_{3}-\mathrm{Im}-\mathrm{Py}\right)_{2} \mathrm{WO}_{4}$.

to carboxylic acid or ester. Furfuryl alcohol, as a well-known challenging heteroaromatic alcohol, was oxidized selectively to furfural (Table 2, entry 19). Aliphatic alcohols represented lower efficiency under similar oxidation reaction conditions than benzyl alcohols (Table 2, entries 20-22).

With successful alcohol oxidation, we studied the utility of $\left(\gamma-\mathrm{Fe}_{2} \mathrm{O}_{3}-\mathrm{Im}-\mathrm{Py}\right)_{2} \mathrm{WO}_{4}$ in the synthesis of 2 -amino3-cyano-4H-chromenes via a multicomponent tandem oxidation process (Fig. 9). Thus, the reaction between benzyl alcohol, malononitrile and dimedone was selected as a model reaction to find the optimum amount of the catalyst (Table 3, entries 1-4). The best result was reached using $5 \mathrm{~mol} \%$ of the catalyst (Table 3 , entry 4 ). 

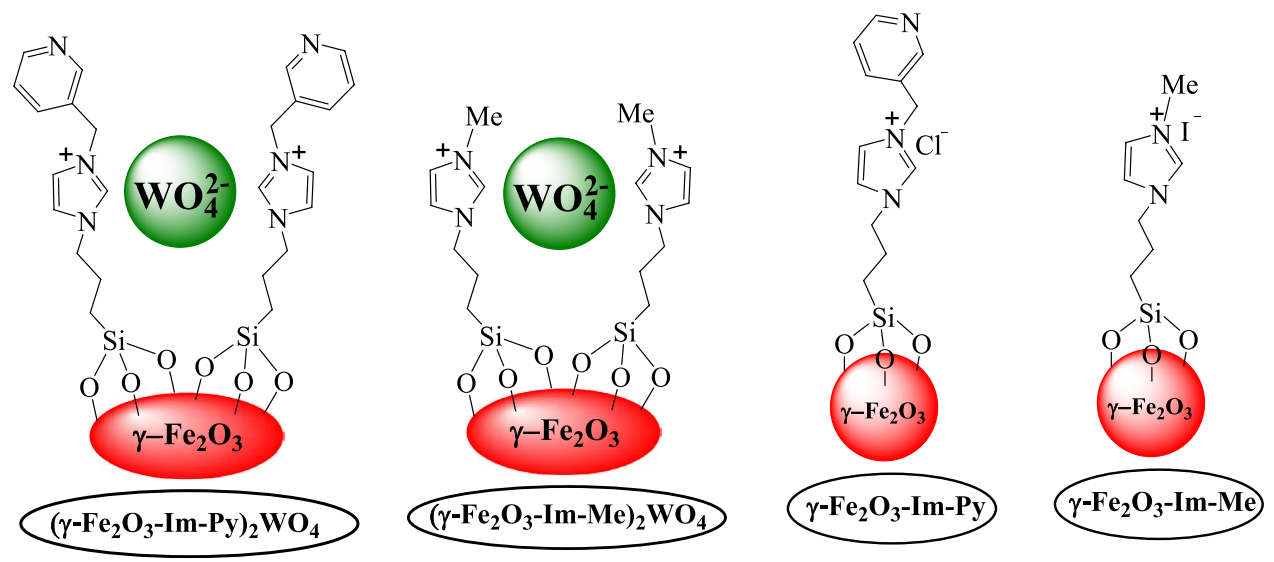

Figure 12. Chemical structure of $\left(\gamma-\mathrm{Fe}_{2} \mathrm{O}_{3}-\mathrm{Im}-\mathrm{Py}\right)_{2} \mathrm{WO}_{4},\left(\gamma-\mathrm{Fe}_{2} \mathrm{O}_{3}-\mathrm{Im}-\mathrm{Me}\right)_{2} \mathrm{WO}_{4}, \gamma-\mathrm{Fe}_{2} \mathrm{O}_{3}-\mathrm{Im}-\mathrm{Py}$ and $\gamma-\mathrm{Fe}_{2} \mathrm{O}_{3}$ Im-Me.

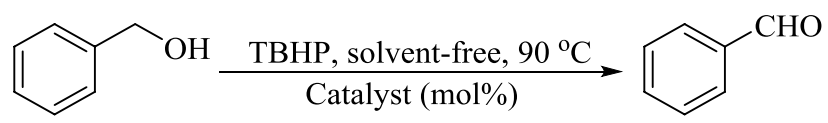

Figure 13. Role of the catalyst in the oxidation of benzyl alcohol.

\begin{tabular}{|l|l|l|l|}
\hline Entry & Catalyst & Time (h) & Yield $^{\mathrm{a}}$ (\%) \\
\hline $1^{\mathrm{b}}$ & $\left(\gamma-\mathrm{Fe}_{2} \mathrm{O}_{3}-\mathrm{Im}-\mathrm{Me}\right)_{2} \mathrm{WO}_{4}(2 \mathrm{~mol} \%, 57 \mathrm{mg})$ & 3 & 98 \\
\hline 2 & $\gamma-\mathrm{Fe}_{2} \mathrm{O}_{3}-\mathrm{Im}-\mathrm{Py}(57 \mathrm{mg})$ & 24 & 27 \\
\hline 3 & $\gamma-\mathrm{Fe}_{2} \mathrm{O}_{3}(57 \mathrm{mg})$ & 24 & 27 \\
\hline $4^{\mathrm{b}}$ & $\mathrm{Na}_{2} \mathrm{WO}_{4} \cdot 2 \mathrm{H}_{2} \mathrm{O}(2 \mathrm{~mol} \%, 6.6 \mathrm{mg})$ & 24 & 41 \\
\hline 5 & $\mathrm{Py}(2 \mathrm{~mol} \%, 1.58 \mathrm{mg})$ & 24 & Trace \\
\hline 6 & - & 24 & Trace \\
\hline $7^{\mathrm{b}}$ & $\left(\gamma-\mathrm{Fe}_{2} \mathrm{O}_{3}-\mathrm{Im}-\mathrm{Py}_{2} \mathrm{MoO}_{4}(2 \mathrm{~mol} \%, 64 \mathrm{mg})\right.$ & 3 & 96 \\
\hline $8^{\mathrm{b}}$ & $\gamma-\mathrm{Fe}_{2} \mathrm{O}_{3}-\mathrm{Im}-\mathrm{Py}_{-} \mathrm{VO}_{3}(2 \mathrm{~mol} \%, 31 \mathrm{mg})$ & 3 & 98 \\
\hline
\end{tabular}

Table 5. The effect of different catalysts on the oxidation of benzyl alcohol. ${ }^{a}$ Isolated yield. Reaction conditions: benzyl alcohol $(1 \mathrm{mmol}), \mathrm{TBHP}(6 \mathrm{mmol})$ at $90^{\circ} \mathrm{C}$. ${ }^{\mathrm{b}}$ Amount of the catalyst is based on W, Mo or V contents, relative to benzyl alcohol.<smiles>CC1(C)CC(=O)C2=C(C1)OC(N)=C(C#N)C2c1ccccc1</smiles>

Figure 14. Role of the catalyst in the synthesis of 2-amino-3-cyano-4H-chromene from benzyl alcohol.

\begin{tabular}{|l|l|l|l|}
\hline Entry & Catalyst $^{\mathbf{a}}(\mathbf{m o l} \%)$ & Time $(\mathbf{I}+\mathbf{I I}, \mathbf{h})$ & Yield $^{\mathbf{b}}(\%)$ \\
\hline 1 & $\left(\gamma-\mathrm{Fe}_{2} \mathrm{O}_{3}-\mathrm{Im}-\mathrm{Py}\right)_{2} \mathrm{WO}_{4}$ & $1.5+4$ & 91 \\
\hline 2 & $\left(\gamma-\mathrm{Fe}_{2} \mathrm{O}_{3}-\mathrm{Im}-\mathrm{Me}\right)_{2} \mathrm{WO}_{4}$ & $1.5+6$ & 50 \\
\hline
\end{tabular}

Table 6. The effect of different catalysts in the synthesis of 2-amino-3-cyano- $4 H$-chromene from benzyl alcohol. a Amount of the catalyst $(5 \mathrm{~mol} \%, 142 \mathrm{mg}$ ) is based on $\mathrm{W}$ content and relative to benzyl alcohol. ${ }^{b}$ Reaction conditions: (I) benzyl alcohol (1 mmol), TBHP $(6 \mathrm{mmol})$, catalyst, neat, $90^{\circ} \mathrm{C}$; and (II) malononitrile $(1.2 \mathrm{mmol})$, dimedone $(1.2 \mathrm{mmol})$, neat, $90^{\circ} \mathrm{C}$. 


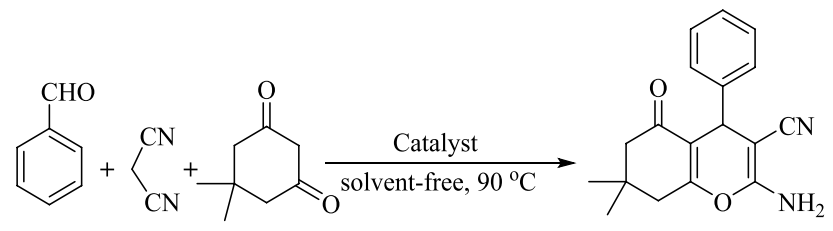

Figure 15. Role of the catalyst in the synthesis of 2-amino-3-cyano-4H-chromene from benzaldehyde.

\begin{tabular}{|l|l|l|l|}
\hline Entry & Catalyst & Time (h) & Yield $^{\text {a }}(\%)$ \\
\hline $1^{\mathrm{b}}$ & $\left(\gamma-\mathrm{Fe}_{2} \mathrm{O}_{3}-\mathrm{Im}-\mathrm{Py}\right)_{2} \mathrm{WO}_{4}$ & 1.5 & 95 \\
\hline 2 & $\gamma-\mathrm{Fe}_{2} \mathrm{O}_{3}-\mathrm{Im}-\mathrm{Py}$ & 1.5 & 95 \\
\hline 3 & $\gamma-\mathrm{Fe}_{2} \mathrm{O}_{3}-\mathrm{Im}-\mathrm{Me}$ & 2.5 & 50 \\
\hline
\end{tabular}

Table 7. The effect of different catalysts in the synthesis of 2-amino-3-cyano- $4 H$-chromene from benzaldehyde. ${ }^{a}$ Reaction conditions: benzaldehyde $(1 \mathrm{mmol})$, malononitrile $(1.2 \mathrm{mmol})$, dimedone $(1.2$ $\mathrm{mmol})$, catalyst $(142 \mathrm{mg})$, neat, $90{ }^{\circ} \mathrm{C}$. ${ }^{\mathrm{b}}$ Amount of the catalyst $(5 \mathrm{~mol} \%, 142 \mathrm{mg})$ is based on W content and relative to alcohol.

The reactions of a variety of aromatic/aliphatic alcohol, malononitrile and dimedone were studied using optimum reaction conditions (Fig. 10, Table 4). Benzyl alcohol having electron-withdrawing or -releasing groups underwent the reaction with malononitrile and dimedone with high efficiency to give 2-amino-3-cyano- $4 \mathrm{H}$ chromenes in good to high yields. Based on these results, the reaction progress was not sensitive to the electron density of the substrates. Several substituents on the benzyl alcohol such as methoxy, methyl, nitro, chloride and bromide were remained intact during the reaction (Table 4, entries 1-10). The reaction of furfuryl alcohol as a heteroaromatic alcohol and cinnamyl alcohol as an $\alpha, \beta$-unsaturated alcohol progressed well (Table 4, entries 11 and 12). 1-Octanol as an aliphatic alcohol was also condensed with malononitrile and dimedone successfully (Table 4, entry 13). Moreover, the reaction of $\beta$-dicarbonyl compounds such as cyclohexane-1,3-dione, pentane2,4-dione, methyl acetoacetate and ethyl acetoacetate were investigated using the present method and desired products were obtained in good yields (Table 4, entries 14-17). The reactions are clean without formation of any side products especially the overoxidation products such as carboxylic acids or esters, which can be formed from alcohols during oxidation reaction. These observations showed the high catalytic activity and selectivity of the catalyst.

In addition, the applicability of this protocol was evaluated for the activated compounds such as $\alpha$-naphthol, $\beta$-naphthol and 4-hydrxycoumarin (Fig. 11) and the products were obtained in good to high yields.

To prove the role of the catalyst during the oxidation reaction, the oxidation reaction of benzyl alcohol was assessed in the presence of $\left(\gamma-\mathrm{Fe}_{2} \mathrm{O}_{3} \text {-Im-Me) }\right)_{2} \mathrm{WO}_{4}$ (pyridine-free catalyst), $\gamma-\mathrm{Fe}_{2} \mathrm{O}_{3}$-Im-Py (tungstate-free catalyst) and $\gamma-\mathrm{Fe}_{2} \mathrm{O}_{3}$ (Figs. 12 and 13). It was found that the reactions were proceeded in 98, 27 and $27 \%$ yields, respectively (Table 5, entries 1-3). These results showed the special effect of tungstate in the oxidation reaction and any role of pyridine in this process. A similar reaction in the presence of sodium tungstate produced the desired product in low yield ( $24 \mathrm{~h}, 41 \%$ ) (Table 5, entry 4 ), which showed the activation effect of supported imidazolium species on the tungstate groups. Moreover, the reaction under catalyst-free conditions or in the presence of pyridine produced only a trace amount of the product in $24 \mathrm{~h}$ (Table 5, entries 5 and 6). The oxidation reaction of benzyl alcohol in presence of $\left(\gamma-\mathrm{Fe}_{2} \mathrm{O}_{3}-\mathrm{Im}-\mathrm{Py}\right)_{2} \mathrm{MoO}_{4}$ and $\gamma-\mathrm{Fe}_{2} \mathrm{O}_{3}-\mathrm{Im}-\mathrm{Py}-\mathrm{VO}_{3}$, varying two different oxidizing anions, was also examined (Table 5, entries 7 and 8) and the same results as in the presence of $\left(\gamma-\mathrm{Fe}_{2} \mathrm{O}_{3}-\mathrm{Im}-\mathrm{Py}\right)_{2} \mathrm{WO}_{4}$ were obtained.

To demonstrate the role of the catalyst in the TOP synthesis of 2-amino-3-cyano-4H-chromene (Fig. 14), the model reaction was surveyed with $\left(\gamma-\mathrm{Fe}_{2} \mathrm{O}_{3}-\mathrm{Im}-\mathrm{Me}\right)_{2} \mathrm{WO}_{4}$ as the pyridine-free analogues catalyst (Fig. 12). The product was obtained in a moderate yield (50\%), which shows the importance of the pyridine effect on the Knoevenagel condensation-Michael addition-cyclization reaction of the in-situ formed aldehyde with malononitrile and dimedone (Table 6, entry 2).

The effect of the catalyst in the Knoevenagel condensation-Michael addition-cyclization step of the synthesis of 2-amino-3-cyano- $4 \mathrm{H}$-chromenes was also studied by performing the reaction of benzaldehyde, malononitrile and dimedone (Fig. 15) using $\left(\gamma-\mathrm{Fe}_{2} \mathrm{O}_{3} \text {-Im-Py) }\right)_{2} \mathrm{WO}_{4}, \gamma-\mathrm{Fe}_{2} \mathrm{O}_{3}$-Im-Py (tungstate-free catalyst) and $\gamma-\mathrm{Fe}_{2} \mathrm{O}_{3}$ Im-Me (tungstate and pyridine-free catalyst) (Fig. 12, Table 7). Any effect of tungstate was not observed in the Knoevenagel condensation-Michael addition-cyclization reaction. Therefore, in this step, the most active site of the catalyst should be pyridine and imidazolium moiety.

A plausible mechanism was estimated for the reaction based on our results and proposed mechanisms in the literature ${ }^{81-84}$. Firstly, aldehydes are produced from alcohols by the dehydration in the presence of TBHP catalysed by tungstate ions. In the next step, the catalyst enables the formation of dicyanoolefins (A) by Knoevenagel condensation of in-situ formed aldehydes with malononitrile. Then, Michael addition of enolate of dimedone (B) to dicyanoolefins leads to the formation of $\mathrm{C}$, followed by cyclocondensation and tautomerization to form 2-amino-3-cyano- $4 \mathrm{H}$-chromenes (Fig. 16). During this process, imidazolium cations activate electrophiles (aldehyde and malononitrile) by hydrogen-bond formation between the carbonyl and nitrile groups with 


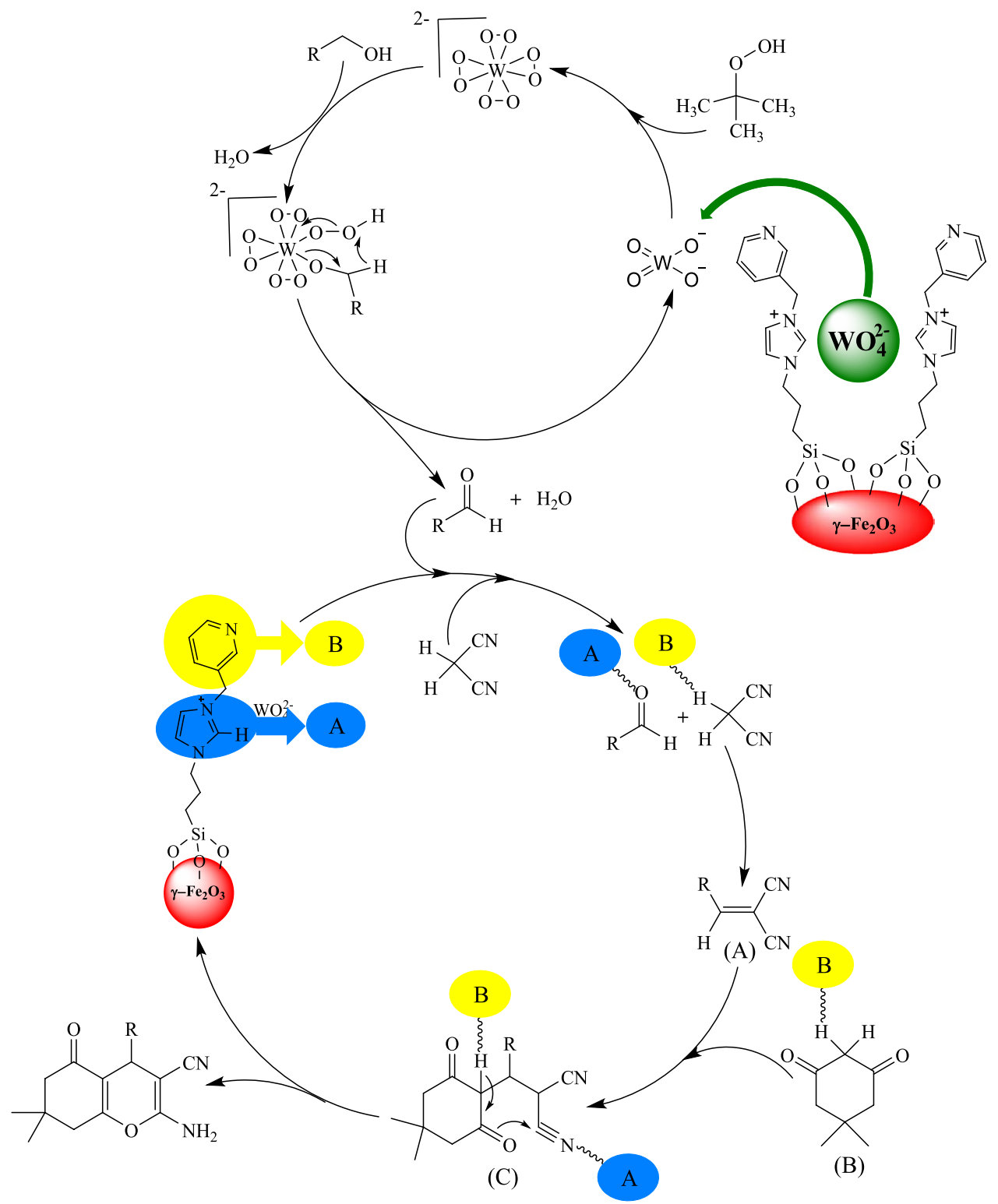

Figure 16. Proposed mechanism pathway for the preparation of functionalized- $4 H$-chromenes via a multicomponent TOP catalyzed by $\left(\gamma-\mathrm{Fe}_{2} \mathrm{O}_{3}-\mathrm{Im}-\mathrm{Py}\right)_{2} \mathrm{WO}_{4}$ as a multifunctional catalyst.

$\mathrm{OH}_{\frac{1}{2)} \text { Catalyst, TBHP, solvent-free, } 90^{\circ} \mathrm{C}}$ malononitrile

Figure 17. Reaction between benzyl alcohol and malononitrile for the synthesis of 2-benzylidenemalononitrile.

\begin{tabular}{|l|l|l|l|}
\hline Entry & Catalyst $^{\mathbf{a}}$ & Time $(\mathbf{I}+\mathbf{I I}, \mathbf{h})$ & Yield $^{\mathbf{b}}(\%)$ \\
\hline 1 & $\left(\gamma-\mathrm{Fe}_{2} \mathrm{O}_{3}-\mathrm{Im}-\mathrm{Py}\right)_{2} \mathrm{WO}_{4}$ & $1.5+2.5$ & 93 \\
\hline 2 & $\left(\gamma-\mathrm{Fe}_{2} \mathrm{O}_{3}-\mathrm{Im}-\mathrm{Me}\right)_{2} \mathrm{WO}_{4}$ & $1.5+5.5$ & 57 \\
\hline
\end{tabular}

Table 8. The effect of different catalysts in the synthesis of 2-benzylidenemalononitrile from benzyl alcohol. ${ }^{a}$ Amount of the catalyst is based on W content and relative to benzyl alcohol. ${ }^{b}$ Reaction conditions: (I) benzyl alcohol (1 mmol), TBHP (6 mmol), catalyst $(5 \mathrm{~mol} \%, 142 \mathrm{mg})$, neat, $90^{\circ} \mathrm{C}$; and (II) malononitrile $(1.2 \mathrm{mmol})$. 


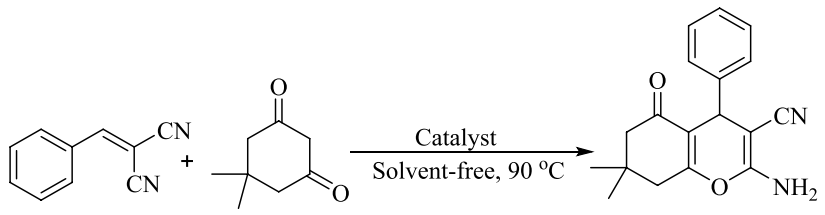

Figure 18. Reaction between 2-benzylidenemalononitrile and dimedone for synthesis of 2-amino-3-cyano-4Hchromene.

\begin{tabular}{|l|l|l|l|}
\hline Entry & Catalyst $^{\mathbf{a}}(\mathbf{m o l} \%)$ & Time (min) & Yield $^{\mathbf{b}}(\%)$ \\
\hline 1 & $\left(\gamma-\mathrm{Fe}_{2} \mathrm{O}_{3}-\mathrm{Im}-\mathrm{Py}\right)_{2} \mathrm{WO}_{4}$ & 30 & 96 \\
\hline 2 & $\left(\gamma-\mathrm{Fe}_{2} \mathrm{O}_{3}-\mathrm{Im}-\mathrm{Me}\right)_{2} \mathrm{WO}_{4}$ & 90 & 73 \\
\hline
\end{tabular}

Table 9. The effect of different catalysts in the synthesis of 2-amino-3-cyano-4H-chromene from benzyl alcohol. a Amount of the catalyst is based on $\mathrm{W}$ content and relative to benzyl alcohol. ${ }^{\mathrm{b}}$ Reaction conditions: 2-benzylidenemalononitrile $(1 \mathrm{mmol})$, dimedone $(1 \mathrm{mmol})$, catalyst $(5 \mathrm{~mol} \%, 142 \mathrm{mg})$, neat, $90{ }^{\circ} \mathrm{C}$.

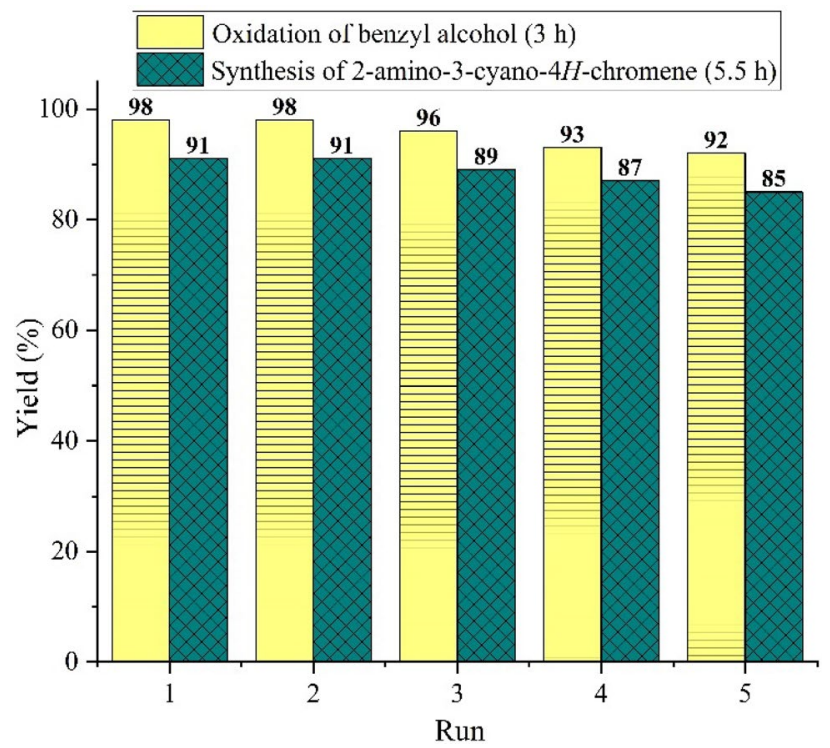

Figure 19. Recyclability of $\left(\gamma-\mathrm{Fe}_{2} \mathrm{O}_{3} \text {-Im-Py }\right)_{2} \mathrm{WO}_{4}$ catalyst in the oxidation of benzyl alcohol and also in the preparation of functionalized 2-amino-3-cyano- $4 \mathrm{H}$-chromene via multicomponent TOP in the model reaction, under optimized reaction conditions.

the hydrogen at the 2-position of the imidazolium ring. At the same time, pyridine activates nucleophiles by removing the acidic hydrogens from these compounds. The dual activation of nucleophiles and electrophiles by the imidazolium and pyridine is essential to promote the reaction in good to high yields. This activation effect can be clearly observed in the synthesis of 2-amino-3-cyano- $4 H$-chromenes from the in-situ formed aldehydes containing electron-resealing or electron-withdrawing groups in good to high yields, regardless of the electron density of the substrates (Table 4, entries 1-10).

The probability of formation of dicyanoolefins (A) (Fig. 16) as an intermediate in the reaction was studied by performing the catalytic reaction of benzyl alcohol with malononitrile in the presence of $\left(\gamma-\mathrm{Fe}_{2} \mathrm{O}_{3}-\mathrm{Im}-\mathrm{Py}\right)_{2} \mathrm{WO}_{4}$ under optimized reaction conditions (Fig. 17). 2-Benzylidenemalononitrile, was isolated in $93 \%$ yield (Table 8 , entry 1) and characterized by its ${ }^{1} \mathrm{H}$ NMR spectrum (Supplementary Fig. S15). A reaction between 2-benzylidenemalononitrile and dimedone in the presence of catalyst was also conducted (Fig. 18) and 2-amino-3cyano- $4 H$-chromene was isolated in $96 \%$ yield (Table 9, entry 1 ). These results clearly confirmed the formation of Knoevenagel condensation product (A), as an intermediate in the TOP synthesis of 2-amino-3-cyano- $4 \mathrm{H}$ chromenes from alcohols. Similar reactions in the presence of $\left(\gamma-\mathrm{Fe}_{2} \mathrm{O}_{3}-\mathrm{Im}-\mathrm{Me}\right)_{2} \mathrm{WO}_{4}$ as pyridine-free analogue of the catalyst produced the desired product in lower yield (Tables 8 and 9, entry 2), which showed the special role of pyridine as a base in the Knoevenagel and sequential Michael addition-cyclization reactions. 

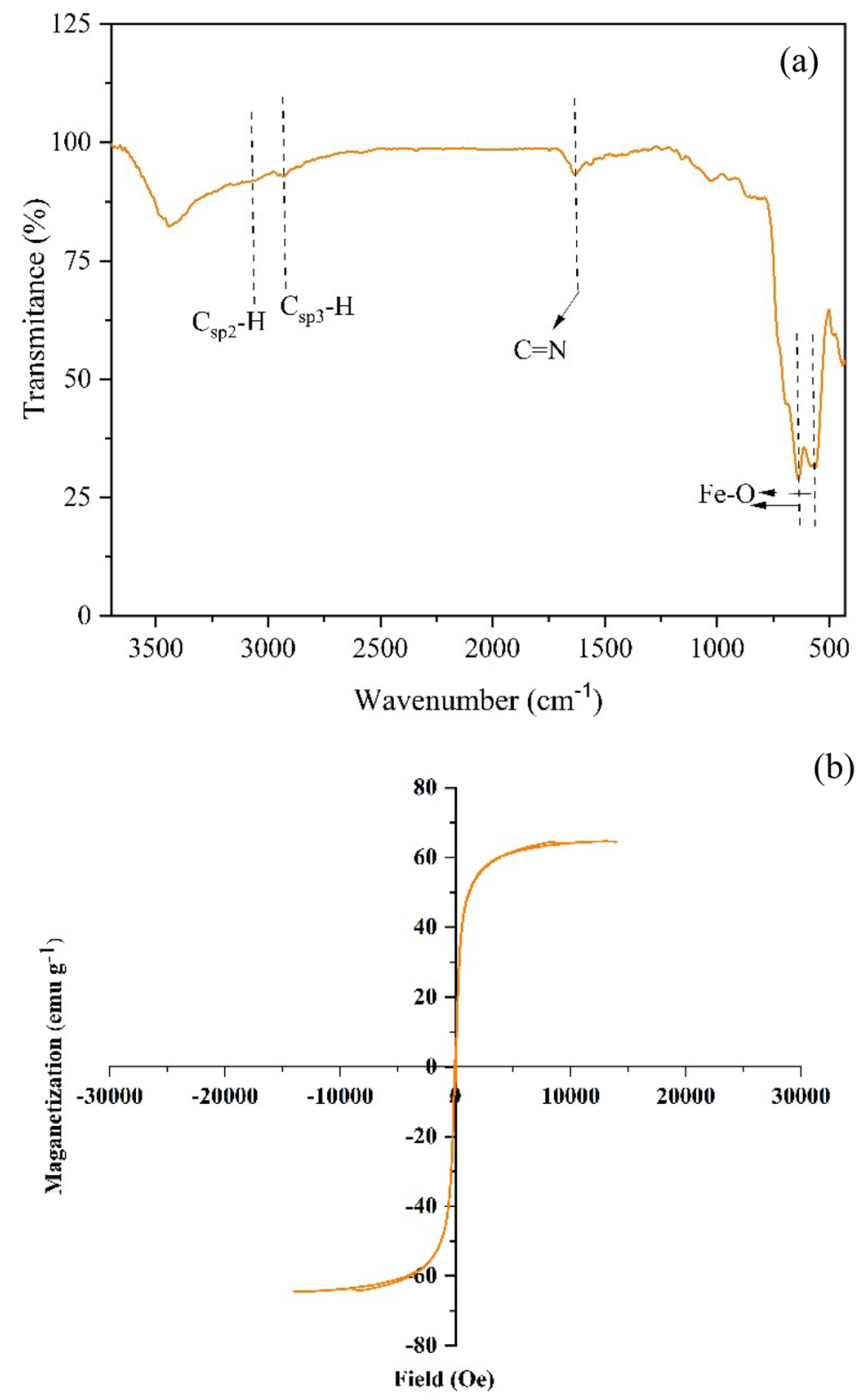

(b)

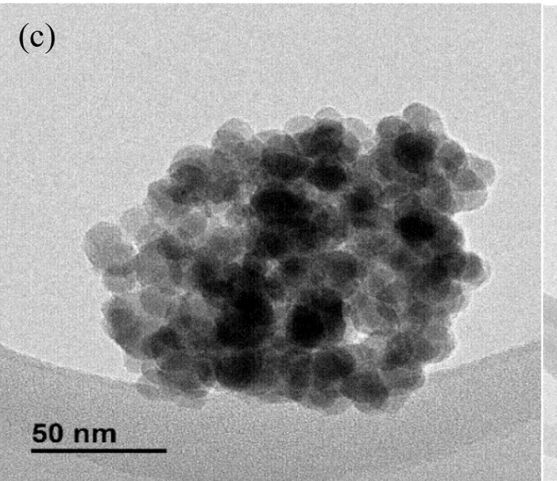

(d)

Figure 20. (a) FT-IR spectrum (b) VSM curve and (c,d) TEM images of $\left(\gamma-\mathrm{Fe}_{2} \mathrm{O}_{3}\right.$-Im-Py) ${ }_{2} \mathrm{WO}_{4}$ after 5 th run reuse in the synthesis of 2-amino-3-cyano- $4 H$-chromenes via multicomponent TOP. 
The catalyst recyclability and reusability were examined in the oxidation of benzyl alcohol and also in the preparation of functionalized 2-amino-3-cyano- $4 \mathrm{H}$-chromene via multicomponent TOP in the model reaction, under optimized reaction conditions. Ethyl acetate was added to the completed reaction and $\left(\gamma-\mathrm{Fe}_{2} \mathrm{O}_{3^{-}}\right.$ $\mathrm{Im}-\mathrm{Py})_{2} \mathrm{WO}_{4}$ was isolated simply using an external magnet, washed with EtOAc and EtOH. Then, the catalyst dried in a vacuum oven, and recycled again for another new batch. After five consecutive runs, the catalyst still showed high catalytic performance (Fig. 19). To demonstrate that $\left(\gamma-\mathrm{Fe}_{2} \mathrm{O}_{3}-\mathrm{Im}-\mathrm{Py}\right)_{2} \mathrm{WO}_{4}$ is truly heterogeneous, a leaching experiment was directed. Analysis of the reaction mixture by ICP after catalyst separation showed that the leaching was very low, so that after the $5^{\text {th }}$ recovery, the leaching amount of tungsten was less than $0.3 \mathrm{ppm}$. The result of ICP showed that $\left(\gamma-\mathrm{Fe}_{2} \mathrm{O}_{3}-\mathrm{Im}-\mathrm{Py}\right)_{2} \mathrm{WO}_{4}$ is truly heterogeneous and catalyst leaching is negligible under this reaction condition. FT-IR (Fig. 20a), VSM (Fig. 20b) and TEM images (Fig. 20c,d) of the recycled $\left(\gamma-\mathrm{Fe}_{2} \mathrm{O}_{3}-\mathrm{Im}-\mathrm{Py}\right)_{2} \mathrm{WO}_{4}$ after five runs also revealed the significant stability of the catalyst.

Considering the importance of large-scale reactions, in the last part, we have evaluated the scalability of the oxidation reaction and muticomponent TOP synthesis of 2 -amino-3-cyano- $4 H$-chromenes. To do this, the oxidaton reaction of benzyl alcohol and also muticomponent TOP of benzyl alcohol, malononitrile and dimedone in a scaled-up procedure (50 times) in the presence of $\left(\gamma-\mathrm{Fe}_{2} \mathrm{O}_{3}-\mathrm{Im}-\mathrm{Py}\right)_{2} \mathrm{WO}_{4}$ was carried out successfully under the optimized reaction conditions. Interestingly, the scaled-up reaction accompanied with 95 and $88 \%$ isolated yields of the desired products.

\section{Conclusion}

In this study, we have designed and synthesized a novel base-metal multifunctional catalyst $\left[\left(\gamma-\mathrm{Fe}_{2} \mathrm{O}_{3}\right.\right.$-Im$\mathrm{Py})_{2} \mathrm{WO}_{4}$ ]. This multifunctional heterogeneous nanocatalyst is completely characterized by various techniques such as FT-IR, XPS, TEM, FESEM, ICP, TGA, VSM and XRD. Then, its catalytic activity was evaluated in the synthesis of 2-amino-3-cyano- $4 H$-chromenes via a multicomponent tandem oxidation process starting from alcohols as suitable alternatives for integrate consideration of economic viability and environmental integrity. Different types of 2-amino-3-cyano- $4 \mathrm{H}$-chromenes were produced in good to high yields by the reaction of different types of in-situ formed aldehydes with malononitrile, and $\beta$-dicarbonyl compounds/naphthols/4-hydroxycumarin under solvent-free conditions. The catalyst operated by a dual activation of nucleophiles and electrophiles and was readily separated from the reaction mixture and reused in five cycles with high degree of efficiency. The high efficiency of the catalyst is related to the tandem catalytic effect of tungstate in the oxidation of alcohols and the basic role of pyridine and imidazolium sites in the Knoevenagel condensation-Michael addition-cyclization reaction of in-situ formed aldehydes with malononitrile and activated nucleophilic components.

Received: 8 October 2021; Accepted: 1 February 2022

Published online: 21 February 2022

\section{References}

1. Lee, J. M., Na, Y., Han, H. \& Chang, S. Cooperative multi-catalyst systems for one-pot organic transformations. Chem. Soc. Rev. 33, 302-312 (2014).

2. Wasilke, J. C., Obrey, S. J., Baker, R. T. \& Bazan, G. C. Concurrent tandem catalysis. Chem. Rev. 105, 1001-1020 (2005).

3. Jeena, V. \& Robinson, R. S. Recent developments in one-pot tandem oxidation process coupling reactions. RSC Adv. 4, 40720-40739 (2014).

4. Kopylovich, M. N. et al. Catalytic oxidation of alcohols: Recent advances. Adv. Organomet. Chem. 63, 91-174 (2015).

5. Ireland, R. E. \& Norbeck, D. W. Application of the Swern oxidation to the manipulation of highly reactive carbonyl compounds. J. Org. Chem. 50, 2198-2200 (1985).

6. Quesada, E. et al. One-pot conversion of activated alcohols into 1,1-dibromoalkenes and terminal alkynes using tandem oxidation process with manganese dioxide. Tetrahedron 62, 6673-6680 (2006)

7. Majik, M. S., Parameswaran, P. S. \& Tilve, S. G. Total synthesis of (-)- and (+)-Tedanalactam. J. Org. Chem. 74, 6378-6381 (2009).

8. Craven, P. G. \& Taylor, R. J. Total synthesis and structural confirmation of ( \pm )-Cuevaene A. Tetrahedron Lett. 53, 5422-5425 (2012).

9. Alirezvani, Z., Dekamin, M. G. \& Valiey, E. Cu (II) and magnetite nanoparticles decorated melamine-functionalized chitosan: A synergistic multifunctional catalyst for sustainable cascade oxidation of benzyl alcohols/Knoevenagel condensation. Sci. Rep. 9, $1-12$ (2019).

10. Wu, J., Hua, W., Yue, Y. \& Gao, Z. A highly efficient bifunctional catalyst $\mathrm{CoO}_{\mathrm{x}} /$ tri-g- $\mathrm{C}_{3} \mathrm{~N}_{4}$ for one-pot aerobic oxidation-Knoevenagel condensation reaction. Catalysts 10, 712-716 (2020).

11. Li, J. et al. Triazole-directed fabrication of polyoxovanadate-based metal-organic frameworks as efficient multifunctional heterogeneous catalysts for the Knoevenagel condensation and oxidation of alcohols. Dalton Trans. 50, 10082-10091 (2021).

12. Sandupatla, V., Ch, R., Lingareddy, E. \& Raju, D. One-pot synthesis of imines by direct coupling of alcohols and amines over magnetically recoverable $\mathrm{CdFe}_{2} \mathrm{O}_{4}$ nanocatalyst. Mater. Lett. 302, 130417-130423 (2021).

13. Anbardan, S. Z., Mokhtari, J., Yari, A. \& Bozcheloei, A. H. Direct synthesis of amides and imines by dehydrogenative homo or cross-coupling of amines and alcohols catalyzed by Cu-MOF. RSC Adv. 11, 20788-20793 (2021).

14. Shaabani, A. et al. Amino- functionalized MIL-101(Cr) embedded with Co(II) phthalocyanine as a durable catalyst for one-pot tandem oxidative $\mathrm{A}^{3}$ coupling reactions of alcohols. New J. Chem. 42, 4167-4174 (2018).

15. Li, D., Shen, X. \& Lei, J. Metal-free iodine/TEMPO-mediated aerobic oxidative Ugi-type multicomponent reactions with tertiary amines. J. Org. Chem. 85, 2466-2475 (2019).

16. Ali, G. et al. Photooxidation coupled Kabachnik-fields and Biginelli reactions for direct conversion of benzyl alcohols to a-amino phosphonates and dihydropyrimidones. Acta Chim. Slov. 67, 195-202 (2020).

17. Farshid, H. \& Shaabani, A. Magnetic spent coffee ground as an efficient and green catalyst for aerobic oxidation of alcohols and tandem oxidative Groebke-Blackburn-Bienaymé reaction. J. Iran. Chem. Soc. 18, 1199-1209 (2021).

18. Zarate-Roldan, S., Gimeno, M. C. \& Herrera, R. P. Unconventional gold-catalyzed one-pot/multicomponent synthesis of propargylamines starting from benzyl alcohols. Catalysts 11, 513-525 (2021).

19. Faisca Philips, A. M., Pombeiro, A. J. \& Kopylovich, M. N. Recent advances in cascade reactions initiated by alcohol oxidation. ChemCatChem 9, 217-246 (2017).

20. Jagadeesan, D. Multifunctional nanocatalysts for tandem reactions: A leap toward sustainability. Appl. Catal. A Gen. 51, 59-77 (2016). 
21. Lohr, T. L. \& Marks, T. J. Orthogonal tandem catalysis. Nat. Chem. 7, 477-482 (2015).

22. Campos, J. F. \& Berteina-Raboin, S. Tandem catalysis: Synthesis of nitrogen-containing heterocycles. Catalysts 10, 631-686 (2020).

23. Song, T. et al. A bifunctional iron nanocomposite catalyst for efficient oxidation of alkenes to ketones and 1,2-diketones. ACS Catal. 10, 4617-4629 (2020).

24. Nasseri, M. A., Rezazadeh, Z., Kazemnejadi, M. \& Allahresani, A. Cu-Mn bimetallic complex immobilized on magnetic NPs as an efficient catalyst for domino one-pot preparation of benzimidazole and Biginelli reactions from alcohols. Catal. Lett. 151, 1049-1067 (2021).

25. Bahadorikhalili, S., Malek, K. \& Mahdavi, M. Efficient one-pot synthesis of phenylimidazo[1,2-a] pyridine derivatives using multifunctional copper catalyst supported on $\beta$-cyclodextrin functionalized magnetic graphene oxide. Appl. Organomet. Chem. 34, e5913 (2020).

26. Costa, M., Dias, T. A., Brito, A. \& Proenca, F. Biological importance of structurally diversified chromenes. Eur. J. Med. Chem. 123, 487-507 (2016).

27. Pratap, R. \& Ram, V. J. Natural and synthetic chromenes, fused chromenes and versatility of dihydrobenzo[h]chromenes in organic synthesis. Chem. Rev. 114, 10476-10526 (2014).

28. Chimenti, F. et al. Synthesis, molecular modeling and selective inhibitory activity against human monoamine oxidases of 3-carboxamido-7-substituted coumarins. J. Med. Chem. 52, 1935-1942 (2009).

29. Keri, R. S., Budagumpi, S., Pai, R. K. \& Balakrishna, R. G. Chromones as a privileged scaffold in drug discovery: A review. Eur. J. Med. Chem. 78, 340-374 (2014).

30. Silambarasan, S. S. \& Nasser, A. J. A. A benign synthesis of 2-amino-3-cyano-4H-benzopyrans via domino reaction. J. Drug Deliv. Ther. 9, 271-279 (2019).

31. Mamaghani, M., Nia, R. H., Tavakoli, F. \& Jahanshahi, P. Recent advances in the MCRs synthesis of chromenes: A review. Curr. Org. Chem. 22, 1704-1769 (2018).

32. Hajiashrafi, T., Karimi, M., Heydari, A. \& Tehrani, A. A. Erbium-organic framework as heterogenous Lewis acid catalysis for Hantzsch coupling and tetrahydro-4H-chromene synthesis. Catal. Lett. 147, 453-462 (2017).

33. Balalaie, S., Ramezanpour, S., Bararjanian, M. \& Gross, J. H. DABCO-catalyzed efficient synthesis of naphthopyran derivatives via one-pot three-component condensation reaction at room temperature. Synth. Commun. 38, 1078-1089 (2008).

34. Maleki, B. \& Sheikh, S. One-pot synthesis of 2-amino-2-chromene and 2-amino-3-cyano- $4 H$-pyran derivatives promoted by potassium fluoride. Org. Prep. Proced. Int. 47, 368-378 (2015).

35. Yang, F. et al. A green and one-pot synthesis of benzo $[g]$ chromene derivatives through a multi-component reaction catalyzed by lipase. RSC Adv. 5, 5213-5216 (2015).

36. Mondal, J. et al. Triazine functionalized ordered mesoporous organosilica as a novel organocatalyst for the facile one-pot synthesis of 2-amino-4H-chromenes under solvent-free conditions. RSC Adv. 2, 11306-11317 (2012).

37. Masesane, I. B. \& Mihigo, S. O. Efficient and green preparation of 2-amino-4H-chromenes by a room-temperature, $\mathrm{Na}_{2} \mathrm{CO}_{3}$-catalyzed, three-Component reaction of malononitrile, benzaldehydes and phloroglucinol or resorcinol in aqueous medium. Synth. Commun. 45, 1546-1551 (2015).

38. Mogharabi-Manzari, M. et al. A laccase heterogeneous magnetic fibrous silica-based biocatalyst for green and one-pot cascade synthesis of chromene derivatives. Eur. J. Org. Chem. 2019, 1741-1747 (2019).

39. Nikpassand, N., Fekri, L. Z. \& Ahmadi, P. Griding synthesis of 2-amino-4H-chromenes using 3,3-(butane-1,4-diyl) bis (1,2-dimethyl-1H-imidazole-3-IUM) Br-CAN as a novel reagent. J. Chil. Chem. Soc. 62, 3399-3402 (2017).

40. Nikpassand, N. \& Fekri, L. Z. An in-situ procedure; Grinding synthesis of $4 H$-benzo[ $h]$ chromene-3-carbonitriles using DBUhydrobromide-perbromide. Curr. Green Chem. 4, 103-107 (2017).

41. Cleveland, J. W., Ronaghi, N. \& Jones, C. W. Design of a bifunctional TEMPO-tertiary amine mesoporous silica catalyst for the three-step cascade synthesis of a chromene derivative. Mol. Catal. 517, 112021-112030 (2022).

42. Tanaka, A., Hashimoto, K. \& Kominami, H. Preparation of $\mathrm{Au} / \mathrm{CeO}_{2}$ exhibiting strong surface plasmon resonance effective for selective or chemoselective oxidation of alcohols to aldehydes or ketones in aqueous suspensions under irradiation by green light. J. Am. Chem. Soc. 134, 14526-14533 (2012).

43. Liu, J., Wu, S. \& Li, Z. Recent advances in enzymatic oxidation of alcohols. Curr. Opin. Chem. Biol. 43, 77-86 (2018).

44. Hunsen, M. Pyridinium chlorochromate catalyzed oxidation of alcohols to aldehydes and ketones with periodic acid. Tetrahedron. Lett. 46, 1651-1653 (2005).

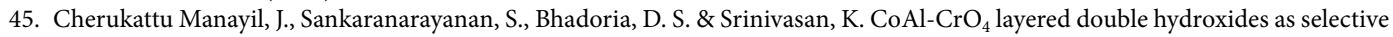
oxidation catalysts at room temperature. Ind. Eng. Chem. Res. 50, 13380-13386 (2011).

46. De Nooy, A. E., Besemer, A. C. \& van Bekkum, H. On the use of stable organic nitroxyl radicals for the oxidation of primary and secondary alcohols. Synthesis 1996, 1153-1176 (1996).

47. Sharma, R. K. et al. Silica-based magnetic manganese nanocatalyst-applications in the oxidation of organic halides and alcohols. ACS Sustain. Chem. Eng. 4, 1123-1130 (2016).

48. Beejapur, H. A., Campisciano, V., Giacalone, F. \& Gruttadauria, M. Catalytic synergism in a $\mathrm{C}_{60} \mathrm{IL}_{10} \mathrm{TEMPO}_{2}$ hybrid in the efficient oxidation of alcohols. Adv. Synth. Catal. 357, 51-58 (2015).

49. Salvo, A. M. P. et al. A simple procedure for the oxidation of alcohols using [bis(acetoxy) iodo] benzene and a catalytic amount of bromide ions in ethyl acetate. Synlett 26, 1179-1184 (2015).

50. Mathew, S., Kumara, C. S. \& Nagaraju, N. Influence of nature of support on the catalytic activity of supported molybdenum-oxo species in benzyl alcohol conversion. J. Mol. Catal. A Chem. 255, 243-324 (2006).

51. Berkessel, A. \& Sklorz, C. A. Mn-trimethyltriazacyclononane/ascorbic acid: A remarkably efficient catalyst for the epoxidation of olefins and the oxidation of alcohols with hydrogen peroxide. Tetrahedron Lett. 40, 7965-7968 (1999).

52. Martın, S. E. \& Garrone, A. Efficient solvent-free iron (III) catalyzed oxidation of alcohols by hydrogen peroxide. Tetrahedron Lett. 44, 549-552 (2003).

53. Liu, J., Wang, F., Sun, K. \& Xu, X. Effective oxidation of alcohols to aldehydes with hydrogen peroxide catalyzed by Pd(OAc) $2 / \mathrm{SO}$ under solvent-free conditions. Catal. Commun. 9, 386-390 (2008).

54. Zauche, T. H. \& Espenson, J. H. Oxidation of alcohols by hydrogen peroxide, catalyzed by methyltrioxorhenium (MTO): A hydride abstraction. Inorg. Chem. 37, 6827-6831 (1998).

55. Kogan, V., Quintal, M. M. \& Neumann, R. Regioselective alkene carbon-carbon bond cleavage to aldehydes and chemoselective alcohol oxidation of allylic alcohols with hydrogen peroxide catalyzed by $\left[\mathrm{cis}-\mathrm{Ru}(\mathrm{II})(\mathrm{dmp})_{2}\left(\mathrm{H}_{2} \mathrm{O}\right)_{2}\right]^{2+}(\mathrm{dmp}=2,9-\mathrm{dimethyl}$ phenanthroline). Org. Lett. 7, 5039-5042 (2005).

56. Hoover, J. M., Ryland, B. L. \& Stahl, S. S. Copper/TEMPO-catalyzed aerobic alcohol oxidation: Mechanistic assessment of different catalyst systems. ACS Catal. 3, 2599-2605 (2013).

57. Vasylyev, M. V. \& Neumann, R. New heterogeneous polyoxometalate based mesoporous catalysts for hydrogen peroxide mediated oxidation reactions. J. Am. Chem. Soc. 126, 884-890 (2004).

58. Karimi, B. et al. Selective oxidation of alcohols with hydrogen peroxide catalyzed by tungstate ions $\left(\mathrm{WO}_{4}\right)$ supported on periodic mesoporous organosilica with imidazolium frameworks (PMO-IL). Tetrahedron 70, 6114-6119 (2014).

59. Liu, D., Gui, J., Sun, Z. \& Park, Y. K. New simple synthesis route for decatungstate hybrids: Novel thermo-regulated phase transfer catalysts for selective oxidation of alcohols. Catal. Lett. 142, 1330-1335 (2012). 
60. Chatel, G. et al. Green, selective and swift oxidation of cyclic alcohols to corresponding ketones. Appl. Catal. A Gen. 478, 157-164 (2014).

61. Mohammadi, M. et al. Ionic-liquid-modified carbon quantum dots as a support for the immobilization of tungstate ions $\left(\mathrm{WO}_{4}\right)$ : Heterogeneous nanocatalysts for the oxidation of alcohols in water. ACS Sustain. Chem. Eng. 7, 5283-5291 (2019).

62. Zohreh, N. et al. Highly dispersible bis-imidazolium/ $/ \mathrm{WO}_{4}$ modified magnetic nanoparticles: A heterogeneous phase transfer catalyst for green and selective oxidations. New J. Chem. 40, 10325-10332 (2016).

63. Rajabi, F., Nafe, M., Bardajee, G. R. \& Luque, R. Tungstate ion $\left(\mathrm{WO}_{4}\right)$ confined in hydrophilic/hydrophobic nanomaterials functionalized Brönsted acidic ionic liquid as highly active catalyst in the selective aerobic oxidation of alcohols in water. Mol. Catal. 497, 111202-111211 (2020).

64. Hosseini Eshbala, F., Mohanazadeh, F. \& Sedrpoushan, A. Tungstate ions $\left(\mathrm{WO}_{4}\right)$ supported on imidazolium framework as novel and recyclable catalyst for rapid and selective oxidation of benzyl alcohols in the presence of hydrogen peroxide. Appl. Organomet. Chem. 31, e3597-3603 (2017).

65. Pourjavadi, A. et al. Tungstate based poly (ionic liquid) entrapped magnetic nanoparticles: A robust oxidation catalyst. Green Chem. 15, 2913-2919 (2013).

66. Sobhani, S., Chahkamali, F. O. \& Sansano, J. M. A new bifunctional heterogeneous nanocatalyst for one-pot reduction-Schiff base condensation and reduction-carbonylation of nitroarenes. RSC Adv. 9, 1362-1372 (2019).

67. Chahkamali, F. O., Sobhani, S. \& Sansano, J. M. Water-dispersible Pd-N-heterocyclic carbene complex immobilized on magnetic nanoparticles as a new heterogeneous catalyst for fluoride-free Hiyama, Suzuki-Miyaura and cyanation reactions in aqueous media. Catal. Lett. https://doi.org/10.1007/s10562-021-03824-0 (2021).

68. Sobhani, S. \& Zarifi, F. Pyridine-grafted graphene oxide: A reusable acid-base bifunctional catalyst for the one-pot synthesis of $\beta$-phosphonomalonates via a cascade Knoevenagel-phospha Michael addition reaction in water. RSC Adv. 5, 96532-96538 (2015).

69. Sobhani, S., Zarifi, F. \& Skibsted, J. Immobilized lanthanum (III) triflate on graphene oxide as a new multifunctional heterogeneous catalyst for the one-pot five-component synthesis of bis(pyrazolyl)methanes. ACS Sustain. Chem. Eng. 5, 4598-4606 (2017).

70. Khazaee, A. et al. Immobilized piperazine on the surface of graphene oxide as a heterogeneous bifunctional acid-base catalyst for the multicomponent synthesis of 2-amino-3-cyano-4H-chromenes. Green Chem. 22, 4604-4616 (2020).

71. Sobhani, S., Ghasemzadeh, M. S. \& Honarmand, M. Piperidine and piperazine immobilized on iron oxide nanoparticles as magnetically recyclable heterogeneous catalysts for one-pot synthesis of $\beta$-phosphonomalonates. Catal. Lett. 4, 1515-1523 (2014).

72. Yuan, X. et al. Cellular distribution and cytotoxicity of graphene quantum dots with different functional groups. Nanoscale Res. Lett. 9, 1-9 (2014)

73. Osadchii, D. Y., Olivos-Suarez, A. I., Bavykina, A. V. \& Gascon, J. Revisiting nitrogen species in covalent triazine frameworks. Langmuir 33, 14278-14285 (2017).

74. Mohamedkhair, A. K., Drmosh, Q. A., Qamar, M. \& Yamani, Z. H. Nanostructured Magnéli-phase $\mathrm{W}_{18} \mathrm{O}_{49}$ thin films for photoelectrochemical water splitting. Catalysts 10, 526-541 (2020).

75. Singh, B. P. et al. Synthesis, characterization and electrocatalytic ability of $\gamma-\mathrm{Fe}_{2} \mathrm{O}_{3}$ nanoparticles for sensing acetaminophen. Indian J. Pure Appl. Phys. 55, 722-728 (2017).

76. Pore, D. M., Undale, K. A., Dongare, B. B. \& Desai, U. V. Potassium phosphate catalyzed a rapid three-component synthesis of tetrahydrobenzo[b]pyran at ambient temperature. Catal. Lett. 132, 104-108 (2009).

77. Sun, W. B. et al. Lithium bromide as a mild, efficient and recyclable catalyst for the one-pot synthesis of tetrahydro- $4 H$-chromene derivatives in aqueous media. Synth. Commun. 40, 587-594 (2010).

78. Yousefi, M. R., Goli-Jolodar, O. \& Shirini, F. Piperazine: An excellent catalyst for the synthesis of 2-amino-3-cyano- $4 \mathrm{H}$-pyrans derivatives in aqueous medium. Bioorg. Chem. 81, 326-333 (2018).

79. Abd El-Rahman, N. M., El-Kateb, A. A. \& Mady, M. F. Simplified approach to the uncatalyzed Knoevenagel condensation and Michael addition reactions in water using microwave irradiation. Synth. Commun. 37, 3961-3970 (2007).

80. Shinde, S., Rashinkar, G. \& Salunkhe, R. DABCO entrapped in agar-agar: A heterogeneous gelly catalyst for multi-component synthesis of 2-amino-4H-chromenes. J. Mol. Liq. 178, 122-126 (2013).

81. Norouzi, M. \& Elhamifar, D. Ionic liquid- modified magnetic mesoporous silica supported tungstate: A powerful and magnetically recoverable nanocatalyst. Compos. Part B Eng. 176, 107308-107318 (2019).

82. Sedrpoushan, A., Hosseini-Eshbala, F., Mohanazadeh, F. \& Heydari, M. Tungstate supported mesoporous silica SBA-15 with imidazolium framework as a hybrid nanocatalyst for selective oxidation of sulfides in the presence of hydrogen peroxide. Appl. Organomet. Chem. 32, e4004-4015 (2018).

83. Wang, Y., Yue, C., Li, X. \& Luo, J. Synthesis of a novel poly (ethylene glycol) grafted triethylamine functionalized dicationic ionic liquid and its application in one-pot synthesis of 2-amino-2-chromene derivatives in water. Comp. Rend. Chim. 19, 1021-1026 (2016).

84. Velasco, J. et al. Imidazolium sulfonates as environmental-friendly catalytic systems for the synthesis of biologically active 2-Amino4H-chromenes: Mechanistic insights. J. Phys. Chem. B 119, 12042-12049 (2015).

\section{Acknowledgements}

We acknowledge the financial support for this research by the University of Birjand Research Council and also access to the XPS facilities of the Central Technical Services of the University of Alicante. This research did not receive any specific grant from funding agencies in the public, commercial, or not-for-profit sectors.

\section{Author contributions}

F.O.C.: Conceptualization, investigation, methodology, writing-original draft; S.S.: Supervision, conceptualization, project administration, resources, writing-review \& editing; J.M.S.: Analysis, writing-review \& editing.

\section{Competing interests}

The authors declare no competing interests.

\section{Additional information}

Supplementary Information The online version contains supplementary material available at https://doi.org/ 10.1038/s41598-022-06759-7.

Correspondence and requests for materials should be addressed to S.S.

Reprints and permissions information is available at www.nature.com/reprints.

Publisher's note Springer Nature remains neutral with regard to jurisdictional claims in published maps and institutional affiliations. 
(c) (i) Open Access This article is licensed under a Creative Commons Attribution 4.0 International cc) License, which permits use, sharing, adaptation, distribution and reproduction in any medium or format, as long as you give appropriate credit to the original author(s) and the source, provide a link to the Creative Commons licence, and indicate if changes were made. The images or other third party material in this article are included in the article's Creative Commons licence, unless indicated otherwise in a credit line to the material. If material is not included in the article's Creative Commons licence and your intended use is not permitted by statutory regulation or exceeds the permitted use, you will need to obtain permission directly from the copyright holder. To view a copy of this licence, visit http://creativecommons.org/licenses/by/4.0/.

(C) The Author(s) 2022 